\title{
Inequality, Leverage and Crises
}

\author{
Michael Kumhof and Romain Rancière
}




\title{
IMF Working Paper
}

Research Department

\section{Inequality, Leverage and Crises}

\section{Prepared by Michael Kumhof and Romain Rancière}

Authorized for distribution by Douglas Laxton

November 2010

\begin{abstract}
This Working Paper should not be reported as representing the views of the IMF.

The views expressed in this Working Paper are those of the author(s) and do not necessarily represent those of the IMF or IMF policy. Working Papers describe research in progress by the author(s) and are published to elicit comments and to further debate.
\end{abstract}

The paper studies how high leverage and crises can arise as a result of changes in the income distribution. Empirically, the periods 1920-1929 and 1983-2008 both exhibited a large increase in the income share of the rich, a large increase in leverage for the remainder, and an eventual financial and real crisis. The paper presents a theoretical model where these features arise endogenously as a result of a shift in bargaining powers over incomes. A financial crisis can reduce leverage if it is very large and not accompanied by a real contraction. But restoration of the lower income group's bargaining power is more effective.

JEL Classification Numbers: E20; E25.

Keywords: Income inequality; consumption inequality; income distribution; distributional conflict; leverage; financial crises; default risk; global solution methods.

Author’s E-Mail Address:mkumhof@imf.org, rranciere@imf.org 


\section{Contents}

I. Introduction ..................... 3

II. Stylized Facts . . . . . . . . . . . . . . . . . . . 5

III. The Model . . . . . . . . . . . . . . . . . . . . . . . . 8

A. Investors . . . . . . . . . . . . . . . . 8

B. Workers . . . . . . . . . . . . . . . . . . . 10

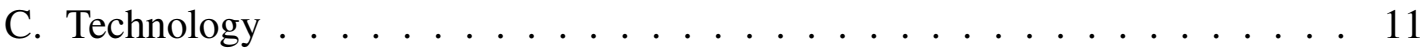

D. Equilibrium . . . . . . . . . . . . . . . . . 12

E. Calibration ........................... 12

F. Solution Methods . . . . . . . . . . . . . . . . . 13

IV. Simulated Scenarios . . . . . . . . . . . . . . . . . . . 15

A. Baseline Scenario . . . . . . . . . . . . . . . . . . 15

B. Uncertainty . . . . . . . . . . . . . . . . . . 17

C. High Leverage - Aggravating Factors . . . . . . . . . . . . . . . 17

D. High Leverage -Solutions . . . . . . . . . . . . . . . . . . 20

E. Further Discussion . . . . . . . . . . . . . . . . . 21

V. Conclusions . . . . . . . . . . . . . . . . . . . 22

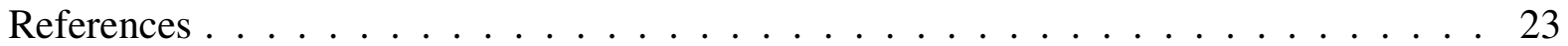

Figures

1. Income Inequality and Household Leverage . . . . . . . . . . . . . . . 26

2. Real Income Inequality . . . . . . . . . . . . . . . . . . . . . 27

3. Income Inequality and Consumption Inequality . . . . . . . . . . . . . . . 28

4. The Variance of Annual, Permanent, and Transitory $(\log )$ Earnings . . . . . . . . 28

5. Debt to Income Ratios . . . . . . . . . . . . . . . . . . . . . . . . . 29

6. The Size of the U.S. Financial Sector . . . . . . . . . . . . . . . . . . . 29

7. Mortgage Debt and Subprime Borrowing . . . . . . . . . . . . 30

8. Mortgage Default - Share of Past Due Loans . . . . . . . . . . . . . . . . . . . . 31

9. Leverage and Crisis Probability in the Model . . . . . . . . . . . . . . . 31

10. Baseline Scenario . . . . . . . . . . . . . . . . . . . . 32

11. Less Capital Investment . . . . . . . . . . . . . . . . . . . 33

12. Nearly Permanent Change in Bargaining Power . . . . . . . . . . . . . . . . . 34

13. High Variable instead of Low Fixed Subsistence Consumption . . . . . . . . . . . 35

14. Orderly Debt Restructuring . . . . . . . . . . . . . . . . . . 36

15. Restoration of Workers' Bargaining Power . . . . . . . . . . . . . . . . 37 


\section{INTRODUCTION}

The United States experienced two major economic crises over the past century-the Great Depression starting in 1929 and the Great Recession starting in 2007. Both were preceded by a sharp increase in income and wealth inequality, and by a similarly sharp increase in debt-to-income ratios among lower- and middle-income households. When those debt-to-income ratios started to be perceived as unsustainable, it became a trigger for the crisis. In this paper, we first document these facts, and then present a dynamic stochastic general equilibrium model in which a crisis driven by income inequality can arise endogenously. The crisis is the ultimate result, after a period of decades, of a shock to the relative bargaining powers over income of two groups of households, investors who account for $5 \%$ of the population, and whose bargaining power increases, and workers who account for $95 \%$ of the population.

The model is kept as simple as possible in order to allow for a clear understanding of the mechanisms at work. The key mechanism is that investors use part of their increased income to purchase additional financial assets backed by loans to workers. By doing so, they allow workers to limit their drop in consumption following their loss of income, but the large and highly persistent rise of workers' debt-to-income ratios generates financial fragility which eventually can lead to a financial crisis. Prior to the crisis, increased saving at the top and increased borrowing at the bottom results in consumption inequality increasing significantly less than income inequality. Saving and borrowing patterns of both groups create an increased need for financial services and intermediation. As a consequence the size of the financial sector, as measured by the ratio of banks' liabilities to GDP, increases. The crisis is characterized by large-scale household debt defaults and an abrupt output contraction as in the 2007 U.S. financial crisis. Because crises are costly, redistribution policies that prevent excessive household indebtedness and reduce crisis-risk ex-ante can be more desirable from a macroeconomic stabilization point of view than ex-post policies such as bailouts or debt restructurings. To our knowledge, our framework is the first to provide an internally consistent mechanism linking the empirically observed rise in income inequality between high income households and poor to middle income households, the increase in household debt-to-income ratios among the latter group, and the risk of a financial crisis.

This paper integrates two strands of literature that have largely been evolving separately: the literature on income and wealth distribution and the literature on financial fragility and macroeconomic volatility. The first literature is mostly focused on accurately describing long run changes in the distribution of income and wealth (Piketty and Saez (2003), Piketty (2010)). One of its main findings is that the most significant changes in the income distribution concern the evolution of top income shares. This feature is taken on board in our model, where income heterogeneity is introduced by considering two groups representing the top stratum and the remainder of the income distribution. 
A companion literature in labor economics seeks to uncover the fundamental factors shaping the change in the income distribution in the United States over the last thirty years. Lemieux, MacLeod and Parent (2009) find that an increase in the share of performance pay (e.g. bonuses) can explain $20 \%$ of the growth in the variance of male wages between the late 1970s and the early 1990s, and almost all of the growth in wage inequality at the very top end of the income distribution. Lemieux (2006) shows that the dramatic increase in the return to post-secondary education plays an important role in the increase in income inequality and can explain why wage gains are disproportionately concentrated at the top of the distribution. Card, Lemieux and Riddell (2004) find that changes in unionization can explain around 14\% of the growth in the variance of male earnings in the United States. Finally, Borjas and Ramey (1995) and Roberts (2010) point to the role of foreign competition and jobs offshoring in the rise of income inequality.

Our paper focuses only on the macroeconomic implications of increased income inequality. Therefore, rather than taking a stand on the microeconomic reasons for that increase, it represents more fundamental shocks by way of a shock to the relative bargaining powers of the two income groups. A similar reduced-form modeling device is employed by Blanchard and Giavazzi (2003), where labor market deregulation is formalized as a reduction in the bargaining power of workers.

The literature on financial fragility has so far ignored the role of income heterogeneity in creating crisis risk. In the canonical Diamond and Dybvig (1983) crisis model, the heterogeneity that matters is that between patient and inpatient consumers. Differences between impatient and patient consumers also feature prominently in financial accelerator models applied to household debt and housing cycles (Iacoviello $(2005,2008)$ ). In this paper we argue that, because increases in household debt-to-income ratios, which increase financial fragility, have been strongly heterogenous across income groups, as documented in Section II, heterogeneity in incomes is a key additional feature that should be explored in models of household debt and financial crises.

While not formally modeled there, the link between income inequality, household indebtedness and crises has been recently discussed in opinion editorials by Paul Krugman, and in books by Rajan (2010) and Reich (2010). Both authors suggest that increases in borrowing have been a way for the poor and the middle-class to maintain or increase their level of consumption at times when their real earnings were stalling. But these authors do not make a formally consistent case for that argument. Our model allows us to do so.

There are of course other candidate explanations for the origins of the 2007 crisis, and many have stressed the roles of excessive financial liberalization and of asset price bubbles. ${ }^{1}$ Typically these factors are found to have been important in the final years preceding the crisis,

\footnotetext{
${ }^{1}$ Keys, Mukherjee, Seru and Vig (2010) discuss the adverse effects of increased securitization on systemic risk. Taylor (2009) claims that the interaction of unusually easy monetary policy with excessive financial liberalization
} 
when debt-to-income ratios increased more steeply than before. But it can also be argued, as done in Rajan (2010), that much of this was simply a manifestation of an underlying and longer-term dynamics driven by income inequality. Rajan's argument is that growing income inequality created political pressure, not to reverse that inequality, but instead to encourage easy credit to keep demand and job creation robust despite stagnating incomes.

It has also been suggested that the increase in wealth of the richest households has played a role in increasing the demand for investment assets. In our model, the financial sector intermediates funds between the increasingly richer top fraction of the population and the increasingly more indebted bottom fraction of the population. As the flow of funds between the two groups increases, so does the size of the financial sector as measured by total assets or total liabilities over GDP. This fact is consistent with recent findings by Philippon (2008). The size of the demand by the top 5\% for bank deposits, in other words for assets backed by household debt, is quantified by directly introducing wealth into their preferences, reflecting a "capitalist spirit" motive stressed by a number of authors starting with Carroll (2000).

A recent literature has attempted to relate the rise in income inequality to the increase in household debt (Krueger and Perri (2006), Iacoviello (2008)). There is an important difference between our approach and that followed by these authors. In their approach an increase in the variance of idiosyncratic income shocks across all households generates a higher demand for insurance in credit markets, thereby increasing household debt. Their approach therefore emphasizes an increase in income inequality experienced equally within each household group, while our paper focuses on the rise in income inequality between two household groups. There is a lively academic debate concerning the relative roles of withinand between-group factors in shaping inequality. But our paper only focuses on one specific type of between-group inequality that can be clearly documented in the data, namely inequality between high income households and everyone else.

The rest of the paper is organized as followed. Section II presents a number of key stylized facts. Section III presents the model. Section IV presents model simulations to study the effects of increasing income inequality, and to discuss policy implications. Section V concludes.

\section{Stylized FACTS}

This section documents a number of key stylized facts regarding the evolution of the distribution of income, wealth and consumption, changes in household debt-to-income ratios overall and for different groups, the size of the financial sector, and household debt default

caused the crisis. Obstfeld and Rogoff (2009) claim that the interaction of these factors with global current account imbalances helped to create a "toxic mix" that helped to set off a worldwide crisis. 
risk during the financial crisis of 2007. The model presented in the next section will be calibrated to broadly replicate these facts.

Income Inequality and Household Debt: 1929 vs. 2007

Figure 1 plots the evolution of income inequality and household debt ratios in the two decades preceding the two major U.S. crises - 1929 and 2007. In both periods income inequality experienced a sharp increase of similar magnitude: the share of total income (excluding capital gains) commanded by the top $5 \%$ of the income distribution increased from $24 \%$ in 1920 to $34 \%$ in 1928, and from $22 \%$ in 1983 to $34 \%$ in 2007. During the same two periods, the ratio of household debt to GNP or to GDP increased dramatically. It almost doubled between 1920 and 1932, and also between 1983 and 2007, when it reached much higher levels than in 1932. In short the joint evolution of income inequality across high and low income groups on the one hand, and of household debt-to-income ratios on the other hand, displays a remarkably similar pattern in both pre-crisis eras.

\section{Income Inequality and Consumption Inequality}

In order to model the consequences of rising income inequality, it is important to clearly document the respective dynamics of income inequality, consumption inequality and wealth inequality. To do so we use a recent comprehensive dataset compiled by Heathcote, Perri and Violante (2010). ${ }^{2}$

Figure 2, top panel, plots the cumulative percentage changes of male hourly real wages between 1967 and 2005 for three deciles of the distribution of wage earnings: the bottom 10 percentile, the percentile surrounding the median, and the top 10 percentile. Figure 2, bottom panel, plots the cumulative percentage change in real male annual earnings for the same three deciles. Both graphs illustrate the large widening of wage inequality over recent decades. The real hourly wages of the top 10 percentile increased sharply by a cumulative $70 \%$, the real hourly wages around the median declined by $5 \%$, while the wages of the bottom $10 \%$ declined strongly, by around $25 \%$. The widening in earnings inequality is even more pronounced when annual earnings are considered reflecting the role of hours and unemployment in the bottom percentile. In the context of our theoretical framework, we take this change in the relative distribution of earnings as the key shock to our model economy.

Figure 3 documents the evolution of inequality in disposable incomes and in non-durable consumption between 1980 and 2006. The graph plots the ratio of disposable incomes and the ratio of non-durable consumption levels between the top and the bottom 10 percentile of the disposable income distribution. An important finding, already stressed by Slescnik (2001) and Krueger and Perri (2006), is that the rise in income inequality has been much more pronounced than the increase in consumption inequality.

\footnotetext{
${ }^{2}$ The rise in U.S. income inequality has been documented since at least Gottshalk and Moffit (1994).
} 


\section{Income Mobility}

To better understand the differences between income inequality and consumption inequality, it is important to assess the importance of intra-generational income mobility. In theory, if increasing income inequality was accompanied by an increase in income mobility, the dispersion in lifetime earnings might be much smaller than the dispersion in annual earnings, as agents move up and down the income ladder throughout their lives. This is a potential explanation for why consumption inequality has been lower than income inequality. However, the data show that, if anything, income mobility has been declining in the United States over the last 40 years, particularly mobility between the top income group and the remainder that we care about in this paper.

A recent study by Kopczuk, Saez and Song $(2010)^{3}$, using micro-level social security data with the sample restricted to men, shows that measures of short-term income mobility (mobility at a five year horizon) and long-term income mobility (lifetime mobility) have been either stable or slightly worsening since the 1950s. As a consequence the evolution of annual income inequality over time is very close to the evolution of longer-term income inequality. They also find that the surge in top earnings is not due to increased mobility between the top income group and other groups. The probability of staying among the top $1 \%$ of earnings after 1,3 or 5 years shows no overall trend since the top share started to be coded in Social Security Data (1978).

In addition, Kopczuk, Saez and Song (2010) show that increases in the variance of annual earnings have been due to increases in the variance of permanent earnings, with only modest increases in the variance of transitory earnings. Figure 4, which uses their data, illustrates this result by plotting, starting in 1970, the variance of annual log earnings, the variance of five-year log earnings (the permanent variance) and the variance of the five-year log earnings deviation (the transitory variance).

These findings together provide support for one of our key simplifying modeling choices, the assumption of two income groups with essentially fixed memberships.

\section{Wealth Inequality and Household Debt-to-Income Ratios}

In the absence of any change in the valuation of household assets and liabilities, a smaller increase in consumption inequality relative to income inequality must imply that households at the bottom of the distribution of income and wealth are becoming more indebted than households at the top. Figure 5 shows the evolution of debt-to-income ratios for the top 5\% and bottom $95 \%$ of households, this time ranked by wealth rather than income, between 1983 and 2007. In 1983, the top wealth group is somewhat more indebted than the bottom group, with a gap of around 15 percentage points. In 2007, the relative debt situation is dramatically

\footnotetext{
${ }^{3}$ See also Bradbury and Katz (2002).
} 
reversed: the debt-to-income ratio of the bottom group, at around 140\%, is now twice as high as the debt-to-income ratio of the top group. Between 1983 and 2007, the debt-to-income ratio of the bottom group has therefore more than doubled while the ratio of the top group has remained fluctuating around $70 \%$. As a consequence almost all of the increase in the debt-to-income ratio at the aggregate level comes from the bottom group of the wealth distribution. Once again this provides very strong motivation for introducing income heterogeneity into a model of household indebtedness and financial fragility.

\section{The Size of the U.S. Financial Sector}

In our theoretical framework, the increase in debt of the bottom $95 \%$ of the distribution generates an increasing need for financial intermediation. Figure 6 plots two measures of the size of the U.S. financial sector between 1980 and 2007. The left panel plots the standard measure of private credit by deposit banks and other financial institutions to GDP. It more than doubled over the period, increasing from $90 \%$ in 1981 to $210 \%$ in 2007 . The right panel plots the share of the financial sector in GDP as constructed by Philippon (2010). According to this measure the financial sector almost doubled in size between 1981 and 2007, and most recently accounted for an extraordinary $8 \%$ of U.S. GDP. A similar pattern was again observed prior to the Great Depression.

\section{Debt-to-Income Ratios, Risk and Financial Crises}

As shown in Figure 7, top panel, most of the increase in debt-to-income ratios for the bottom 95\% group in the period preceding the crisis was associated with mortgage debt. In the mortgage market, the growing share of subprime loans as documented in Figure 7, bottom panel, is an indicator of the increased riskiness that has accompanied higher indebtedness. Figure 8 shows evidence of an increase in mortgage debt default risk following 2007 of a magnitude unprecedented since the Great Depression. Default probabilities that increase with debt-to-income ratios, and default rates of the magnitude observed recently, are key ingredients of our model and its calibration.

\section{THE MODEL}

The model economy consists of two groups of households, referred to as investors and workers, and of a production technology that combines the inputs provided by investors and workers.

\section{A. Investors}

The share of investors in the overall population equals $\chi$, which we will calibrate at $5 \%$. They derive utility from consumption and wealth. 
Utility from consumption $c_{t}^{i}$ has the standard CRRA form, with intertemporal elasticity of substitution $\sigma_{i}$, but is subject to a subsistence, or minimum acceptable, level of consumption $\tilde{c}_{\min }^{i}$. The interpretation of subsistence consumption is that most individuals have arranged their affairs in such a manner that a precipitous drop in consumption would be disastrous, such as a drastic loss of status or, in the case of workers below, destitution and homelessness.

Wealth in the utility function has been used by a number of authors including Carroll (2000), who refers to it as the "capitalist spirit" specification, Reiter (2004), and Piketty (2010). As explained by the latter, it can represent a number of different saving motives. One is as a reduced form for precautionary savings, because wealth provides security in the presence of uninsurable lifetime shocks. Our preferred interpretation is that agents derive direct utility from the prestige, power and social status conferred by wealth. ${ }^{4}$ Wealth in our model can take two forms, physical capital held from period $t$ to $t+1$ and denoted by $k_{t}$, and financial investments, or deposits, held from $t$ to $t+1$ and denoted by $d_{t}$. Utility from deposits is assumed to take the log-form that is common in studies of money demand, but adjusted for expected losses from a crisis event. Utility from physical capital is assumed to take a Stone-Geary form, with utility derived from the logarithm of the sum of physical capital, adjusted for expected losses from a crisis event, and a constant $\bar{k}$ that determines the sensitivity of desired capital investment to changes in income. We will study how our results depend on the value taken by $\bar{k}$. Losses from a crisis event depend on the probability of a crisis in $t+1, \pi_{t}$, which is taken as given by households, known by time $t$, and which will be discussed further below. It also depends on the percentage of the loan or capital stocks destroyed in the event of a crisis, $\left(1-\gamma_{\ell}\right)$ and $\left(1-\gamma_{k}\right)$. The expected loan and capital stocks therefore equal $d_{t}\left(1-\left(1-\gamma_{\ell}\right) \pi_{t}\right)$ and $k_{t}\left(1-\left(1-\gamma_{k}\right) \pi_{t}\right)$, and we have the lifetime utility function

$U_{0}^{i}=E_{0} \sum_{t=0}^{\infty} \beta_{i}^{t}\left[\frac{\left(c_{t}^{i}-\tilde{c}_{\text {min }}^{i}\right)^{\left(1-\frac{1}{\sigma_{i}}\right)}}{\left(1-\frac{1}{\sigma_{i}}\right)}+\xi_{d} \log \left(d_{t}\left(1-\left(1-\gamma_{\ell}\right) \pi_{t}\right)\right)+\xi_{k} \log \left(\bar{k}+k_{t}\left(1-\left(1-\gamma_{k}\right) \pi_{t}\right)\right)\right]$

Investors are the owners of the economy's entire stock of physical capital, whose law of motion is given by

$$
k_{t}=(1-\delta) \Delta_{k_{t}} k_{t-1}+I_{t}
$$

Here $I_{t}$ represents physical investment, and $\Delta_{k_{t}}$ equals $\gamma_{k}<1$ in the event of a crisis, and 1 otherwise. We assume that investors do not engage in wage labor, and instead derive all of their income from their ownership of the physical capital stock and from interest on loans to workers. This assumption is made to keep the model parsimonious, but it is not strictly necessary for our main results and could be relaxed to allow for some wage labor in this

\footnotetext{
${ }^{4}$ Carroll (2000) argues that this wealth-loving motive is the best explanation for why saving rates increase so dramatically with the level of lifetime income. See also Dynan, Skinner and Zeldes (2004) and Kopczuk (2007).
} 
sector. We let $q_{t}$ be the time $t$ price of a deposit that pays off one unit of output in period $t+1$, $\Delta_{\ell_{t}}$ equals $\gamma_{\ell}<1$ in the event of a crisis and 1 otherwise, and we denote the return to capital $k_{t-1}$ by $r_{t}^{k}$. Then the investor's budget constraint is given by

$$
d_{t} q_{t}=\Delta_{\ell_{t}} d_{t-1}+r_{t}^{k} \Delta_{k_{t}} k_{t-1}-c_{t}^{i}-I_{t} .
$$

Investors maximize (1) subject to (2) and (3). Letting $\lambda_{t}^{i}$ be the multiplier of the budget constraint, the optimality conditions for consumption, deposits and capital are given by

$$
\begin{gathered}
\left(c_{t}^{i}-\tilde{c}_{\min }^{i}\right)^{-\frac{1}{\sigma_{i}}}=\lambda_{t}^{i} \\
1=\beta_{i} E_{t}\left(\frac{\lambda_{t+1}^{i}}{\lambda_{t}^{i}}\right) \frac{\left(1-\left(1-\gamma_{\ell}\right) \pi_{t}\right)}{q_{t}}+\frac{\xi_{d}}{\lambda_{t}^{i} d_{t} q_{t}}, \\
1=\beta_{i} E_{t}\left(\frac{\lambda_{t+1}^{i}}{\lambda_{t}^{i}}\right)\left(r_{t+1}^{k}+1-\delta\right)\left(1-\left(1-\gamma_{k}\right) \pi_{t}\right)+\frac{\xi_{k}\left(1-\left(1-\gamma_{k}\right) \pi_{t}\right)}{\lambda_{t}^{i}\left(\bar{k}+k_{t}\left(1-\left(1-\gamma_{k}\right) \pi_{t}\right)\right)} .
\end{gathered}
$$

\section{B. Workers}

The share of workers in the overall population equals $1-\chi$, which we will calibrate at $95 \%$. They derive utility from consumption, with the same CRRA form as investors' consumption utility. We use the same notation as for investors, with the index $w$ replacing the index $i$. Workers inelastically supply one unit of labor per capita. Lifetime utility is given by

$$
U_{0}^{w}=E_{0} \sum_{t=0}^{\infty} \beta_{w}^{t} \frac{\left(c_{t}^{w}-\tilde{c}_{\min }^{w}\right)^{\left(1-\frac{1}{\sigma_{w}}\right)}}{\left(1-\frac{1}{\sigma_{w}}\right)} .
$$

Workers maximize this utility subject to the budget constraint

$$
\ell_{t} q_{t}=\Delta_{\ell_{t}} \ell_{t-1}+c_{t}^{w}-w_{t},
$$

where $\ell_{t}$ denotes loans obtained from investors and $w_{t}$ is the real wage. Workers default on their loan obligations with a positive probability $\pi_{t}$ that is increasing in their debt-to-income ratio according to a logistic function. We will henceforth refer to the debt-to-income ratio as leverage. Default events, or financial crises, are accompanied by real crises in which the capital stock is impaired. We will therefore refer to $\pi_{t}$ not as the default probability but more broadly as the crisis probability. Part of our analysis will consist of experiments that vary the relative sizes of the financial and real components of crises.

The logistic function bounds the crisis probability between 0 and 1 , and over the relevant range it implies a crisis probability that is convex in leverage. The leverage that is relevant for 
the probability of a crisis in period $t+1$ equals the ratio of workers' loans outstanding at the end of period $t$ to their net income in period $t$, where the latter is defined as their time $t$ wage income minus their net interest obligations on loans outstanding between periods $t$ and $t+1$. We have

$$
\pi_{t}=\frac{\exp \left(\phi_{0}+\phi_{1}\left(\frac{\ell_{t}}{w_{t}-\left(\frac{1}{q_{t}}-1\right) \ell_{t}}\right)\right)}{1+\exp \left(\phi_{0}+\phi_{1}\left(\frac{\ell_{t}}{w_{t}-\left(\frac{1}{q_{t}}-1\right) \ell_{t}}\right)\right)} .
$$

We adopt this specification in the interest of keeping the model simple and tractable..$^{5} \mathrm{~A}$ relationship between leverage and crisis probability such as (9) arises endogenously in crisis models such as Schneider and Tornell (2004), where a high enough debt leverage moves the economy to a risky zone where a roll-over debt crisis can occur with positive probability.

Workers' optimality conditions for consumption and loans are given by

$$
\begin{gathered}
\left(c_{t}^{w}-\tilde{c}_{\min }^{w}\right)^{-\frac{1}{\sigma w}}=\lambda_{t}^{w} \\
1=\beta_{w} E_{t}\left(\frac{\lambda_{t+1}^{w}}{\lambda_{t}^{w}}\right) \frac{\left(1-\left(1-\gamma_{\ell}\right) \pi_{t}\right)}{q_{t}}
\end{gathered}
$$

\section{Technology}

The economy's aggregate production function is given by

$$
y_{t}=A\left(\chi \Delta_{t}^{k} k_{t-1}\right)^{\alpha}(1-\chi)^{1-\alpha},
$$

where $A$ is a scale factor that will be used to normalize the economy's calibrated steady state output level. Factor returns are determined by the outcome of a Nash bargaining problem over the real wage. Denoting workers' bargaining power by $\eta_{t}$, we have

$$
\operatorname{Max}_{w_{t}}\left(W_{h_{t}}\right)^{\eta_{t}}\left(K_{h_{t}}\right)^{1-\eta_{t}}
$$

where $W_{h_{t}}=\lambda_{t}^{w} w_{t}$ is the workers' surplus, and $K_{h_{t}}=f_{h_{t}}-w_{t}$ is the investors' surplus. The marginal product of labor $f_{h_{t}}$ is in turn given by

$$
f_{h_{t}}=\frac{(1-\alpha) y_{t}}{(1-\chi)}
$$

The first-order condition of the bargaining problem simplifies to

$$
w_{t}=\eta_{t} f_{h_{t}} .
$$

\footnotetext{
${ }^{5}$ Davig, Leeper and Walker (2010) have, in a different context, adopted an almost identical approach. In their paper the probability of collapse of an initial fiscal regime follows an exogenous logistic function that is increasing in tax rates, and upon collapse the tax rate defaults to an exogenous constant value.
} 
In other words, the real wage equals workers' bargaining power times the marginal product of labor. This implies that $\eta_{t}$ can fall into the interval $\eta_{t} \in\left[0, \frac{1-\chi}{1-\alpha}\right]$. The standard competitive outcome obtains at a bargaining power of one. We assume that workers' bargaining power follows an autoregressive stochastic process that is given by

$$
\eta_{t}=(1-\rho) \bar{\eta}+\rho \eta_{t-1}+e_{t}^{\eta}
$$

Finally, the expected rental rate of capital, which enters into the Euler equation for capital (6), is given by

$$
E_{t}\left[r_{t+1}^{k}\right]=E_{t}\left[\frac{A\left(\chi\left(1-\left(1-\gamma_{k}\right) \pi_{t}\right) k_{t}\right)^{\alpha}(1-\chi)^{1-\alpha}\left(1-\eta_{t+1}(1-\alpha)\right)}{\chi\left(1-\left(1-\gamma_{k}\right) \pi_{t}\right) k_{t}}\right]
$$

\section{Equilibrium}

In equilibrium investors and workers maximize their respective lifetime utilities, and the following market clearing conditions for goods and for financial claims hold:

$$
\begin{gathered}
y_{t}=\chi\left(c_{t}^{i}+I_{t}\right)+(1-\chi) c_{t}^{w}, \\
(1-\chi) \ell_{t}=\chi d_{t} .
\end{gathered}
$$

\section{E. Calibration}

Because our study concerns longer-run phenomena, we calibrate the model at the annual frequency. Utility from consumption takes an identical form across agents, with intertemporal elasticities of consumption equal to $\sigma_{i}=\sigma_{w}=0.5$. The subsistence level of consumption equals $50 \%$ of initial steady-state consumption. The steady-state real interest rate $((1 / \bar{q})-1)$ is fixed at $5 \%$ per annum, similar to values typically used by the RBC literature, by endogenizing workers' time preference $\beta_{w}$. Given the presence of positive capitalist spirit terms in the utility function of investors, $\beta_{i}=0.9$ is lower than $\beta_{w}$. The utility weight on financial wealth $\xi_{d}$ is then determined by imposing an initial steady-state loans-to-income ratio for workers of $64 \%$, consistent with the U.S. value in 1983. The utility weight on physical capital is determined by imposing an initial steady-state gross financial return to

capital of $15 \%$ per annum, equal to the sum of the real interest rate and the depreciation rate $\delta$, which equals $10 \%$ per annum. Finally, the Stone-Geary constant in the utility for physical capital,which affects the elasticity of capital's response to bargaining power shocks, is set at $\bar{k}=-30$. We will experiment with alternative values for $\bar{k}$.

In the aggregate technology, we normalize steady-state output to one through our choice of the parameter $A$. We set the capital share parameter equal to $\alpha=0.27$, which generates a steady-state investment-to-GDP ratio of $18 \%$, consistent with U.S. data. It also implies an initial steady-state income share of investors of $29.8 \%$. As mentioned in Section II, in the 
United States this income share equalled 22\% in the early 1980s and 34\% in recent times. The mean bargaining power $\bar{\eta}=1$ replicates the competitive outcome, and the standard deviation of bargaining power shocks is assumed to equal $\sigma_{\eta}=0.015$. As there is little guidance from the literature regarding an appropriate value for $\sigma_{\eta}$, we will also present the perfect foresight case $\sigma_{\eta}=0$ in our simulations, so that the implications of intermediate values of $\sigma_{\eta}$ can be inferred by comparing the two simulations.

A crisis event is characterized by the probability of its occurrence, and by the size of the collapses in loans and capital, and therefore in output, if it does occur. We set the two coefficients of the logistic function to $\phi_{0}=-7.5$ and $\phi_{1}=3$. As illustrated in Figure 9, this produces a baseline crisis probability of $0.38 \%$ at a leverage of $64 \%$, and a convex relationship between leverage and the crisis probability that reaches almost $5 \%$ at a leverage of $150 \%$. This range is consistent with the probability of major disaster events estimated by Barro (2006), who finds a range of $1 \%-2.5 \%$, and by Rancière, Tornell and Westermann (2008), who estimate $4 \%$ for the period $1980-2000 .{ }^{6}$ Next we calibrate the size of disaster events, that is of major defaults on loans and of output collapses. Based on International Monetary Fund (2009), the reductions in the level of output associated with major financial crises that coincided with real crises have averaged 3.4\%. We generate a comparable output collapse by assuming capital destruction in the event of a crisis equal to $10 \%$ of the pre-existing capital stock, $\gamma_{k}=0.9$. Given the capital share parameter in the technology this leads to an output collapse of around $2.7 \%$. Clearly the ability of our simple model to generate large output collapses is limited by the fact that it does not allow for increases in unemployment at times of crises. To test the sensitivity of our results to the assumption of $\gamma_{k}=0.9$ we will also explore an alternative scenario where the capital destruction only equals $1 \%$, or $\gamma_{k}=0.99$. The percentage of loans defaulted upon during the crisis is based on the U.S. experience, up to this point, with the financial crisis that started in 2007. This crisis has seen mortgage past due rates approaching $10 \%$. We therefore set $\gamma_{\ell}=0.9$.

\section{F. Solution Methods}

The above model has two features that make it unsuitable for the application of conventional perturbation methods. The first is the presence of large and discrete crisis events, which under our calibration imply jumps in state variables of up to $10 \%$. The second is the fact that the model's two endogenous state variables, capital and loans, are extremely persistent, and are then subjected to large bargaining power shocks, which means that they can drift far away from their original steady state for a very long period. It is therefore necessary to apply global solution methods. We adopt and compare two different approaches.

\footnotetext{
${ }^{6}$ Applied to the 2007 crisis this quite low perceived probability seems appropriate given the evident surprise of a majority of commentators at the outbreak of the crisis. It is a separate question whether this assessment was realistic, given the historically unprecedented household leverage ratios in 2007, even when compared to the Great Depression.
} 
First, our model has three continuous state variables (capital, loans and bargaining power) and one binary state variable (crisis or no crisis). This is sufficiently tractable to permit the use of functional iteration on a discretized state space to compute solutions. Specifically, we use the monotone map method of Coleman (1991), which has recently been used in a number of papers by Davig, Leeper and Walker. ${ }^{7}$ The monotone map method discretizes the state space and finds a fixed point in decision rules for each grid point in the state space. It substitutes a set of conjectured decision rules into the model's intertemporal Euler equations, and iterates until the iteration improves the current decision rule at any given state vector by less than some $\varepsilon$. As initial conjectures we use decision rules computed by DYNARE for a first-order approximation of the model. These conjectures are applied to a version of the nonlinear model with only a small fraction of the full standard deviation $\sigma_{\eta}$, and with a narrow grid for the state space, based on the conjecture that for a sufficiently small standard deviation the solutions are approximately linear. Both the standard deviation and the grid width are then sequentially increased, and at each step the results of the previous iteration, appropriately scaled up or down to account for the wider spacing of grid points, are used as initial guesses. Numerical integration is used to compute expectations. As evidence of local uniqueness, we perturb the converged decision rules in various dimensions and check that the algorithm converges back to the same solution.

We present 50-year impulse responses for a standardized realization of bargaining power and crisis shocks, namely an initial decline in workers' bargaining power from $\bar{\eta}=1$ over a period of 10 years, followed by a very gradual return to $\eta=1$, and a crisis event in year 30 . This can be thought of as a highly stylized representation of the events preceding either 1929 or 2007. Sensitivity analysis varies a number of aspects of this shock sequence, including the size of the decline in bargaining power over the first 10 years, the speed of reversal to $\eta=1$ after year 10, the size of the crisis event, the perceived probability of a crisis event, the elasticity of capital accumulation with respect to bargaining power shocks, and the form (fixed or variable) of subsistence consumption.

We also use a second solution method, a perfect foresight solution in TROLL using a Newton-based stacking algorithm ${ }^{8}$, and compare the monotone map simulations with the corresponding perfect foresight simulations. The reason is that this comparison yields interesting additional insights regarding the effects of uncertainty, and regarding the quantitative implications of using different calibrated values for $\sigma_{\eta}$. In the perfect foresight simulation the probability of a crisis event enters optimality conditions in the same way as in the monotone map simulations, but the bargaining power shocks hitting the economy over the first 10 years are unanticipated, and the subsequent evolution of bargaining power is expected with certainty. Specifically, the entire infinite horizon economy is simulated for the first year

\footnotetext{
${ }^{7}$ See Davig (2004), Davig and Leeper (2006, 2007) and Davig, Leeper and Walker (2010).

${ }^{8}$ See Armstrong, Black, Laxton and Rose (1998) and Juillard, Laxton, Pioro and McAdam (1998).
} 
assuming only the first year's shock, which is then repeated for the second year taking as given the state variables inherited from the first year, and so on until year 10, after which no further bargaining power shocks are expected to hit, and slow convergence back to $\eta=1$ occurs, at a rate determined by $\rho$. In period 30, the time of the crisis event, a final infinite horizon simulation, taking as given the values of the state variables, $\gamma_{k} k_{29}$ and $\gamma_{\ell} \ell_{29}$, is performed.

\section{Simulated Scenarios}

Figures 10-15 present a baseline simulation and a number of alternatives that explore the sensitivity of our main conclusions to the calibration of the model. In each case the perfect foresight simulation is shown as a black solid line, and the monotone map simulation as a red dashed line. The horizontal axis represents time, with the shock hitting in year 1 and the final period shown being year 50. Simulations are initiated, both under perfect foresight and under uncertainty, at the steady-state vector of the deterministic steady state (more on this below). The vertical axis shows percent deviations from the initial deterministic steady state for real stock and flow variables, percentage point deviations for rates of return, percentage points for leverage, crisis probability, the interest expense to income ratio, and the income and consumption shares of investors, and simple ratios for the relative per capita income and consumption levels of investors and workers.

\section{A. Baseline Scenario}

Figure 10 presents our baseline scenario, with a cumulative $7.5 \%$ decline in workers' bargaining power over the first 10 years $^{9}$, followed by a very slow reversal back to $\eta=1$ determined by the autogressive parameter $\rho=0.96$. The crisis event happens in year 30, and features $10 \%$ collapses in loans and capital, $\gamma_{\ell}=\gamma_{k}=0.9$.

Apart from some important details that we will discuss in the next subsection, the monotone map and perfect foresight simulation results are very similar. The real wage over the initial decade collapses by close to $6 \%$, while the return to capital increases by over 2 percentage points. Workers' consumption however declines by only around two thirds of the decline in wage income, as workers borrow the shortfall from investors, who have surplus funds to invest following their increase in bargaining power. Over the 30 years prior to the outbreak of the crisis, loans more than double to bring workers' leverage, or debt-to-income ratio, from $64 \%$ to around $140 \%$, with the crisis probability in year 30 exceeding $3 \%$. The loan interest rate for most of this initial period is up to 2 percentage points above its initial value, as lenders arbitrage the return to lending with the now higher return to capital investment.

\footnotetext{
${ }^{9}$ This corresponds to a shock of one half of one standard deviation in each year.
} 
Investors' share of the economy's income increases from initially less than $30 \%$ to over $35 \%$. They have three ways to dispose of the extra income, and they utilize all three in a way that equalizes their marginal contributions to utility. First, their consumption increases by eventually over $20 \%$ prior to the outbreak of the crisis. Second, capital investment increases by over $15 \%$, and so does the physical capital stock. The increase in capital raises the economy's output by eventually close to $4 \%$. And third, loans increase by over $100 \%$, which means that investors' consumption share increases by only around 2 percentage points, compared to 5 percentage points for their income share. These last two points are closely related, because with $71 \%$ of the economy's final demand coming from workers' consumption, this output cannot be sold unless a significant share of the additional income accruing to investors is recycled back to workers by way of loans. With workers' bargaining power, and therefore their ability to service and repay loans, only recovering very gradually, the increase in loans is extremely persistent.

The initial gain in investors' rate of return of more than 2 percentage points is thereafter pared back by two factors. First, the large increase in investment reduces the marginal product of capital, and second, the gradual return of workers' bargaining power increases their wage and thus reduces what is left for capital. By year 30 profitability has in fact declined below its initial level. At that point there are two ways to again raise the return to capital. One would be another round of increasing investors' bargaining power. And the other is a major crisis that destroys large amounts of existing capital. We assume that the latter happens in year 30, but the respite for investors is only temporary in the presence of the ongoing recovery in workers' bargaining power. Unless this changes, the inevitable result will be a prolonged period of low profitability, in the sense of rates of return that remain below those in the initial steady state.

We interpret the crisis as a release of the increasing pressure built up on workers' balance sheets, with the interest portion of debt service increasing from initially around 3\% to $6 \%$ of their income at the time of the crisis, and prospects for an early reduction in leverage very low given the slow recovery in bargaining power. The crisis however barely improves workers' situation. While their loans drop by $10 \%$ due to default, their wage also drops significantly due to the collapse of the real economy, and furthermore the real interest rate on the remaining debt shoots up to raise debt servicing costs to $9 \%$ of income. As a result their leverage ratio barely moves, and for the present calibration it in fact increases further later on so that by year 50 it is above its pre-crisis level, with a very slow reduction thereafter. It is however clear that this last result depends critically on the relative sizes of the loan default versus the collapse in the real economy. As we will see below, when the crisis mainly affects loans, it does bring more significant relief to workers. 


\section{B. Uncertainty}

The simulations based on the monotone map method, which take uncertainty concerning future levels of bargaining power into account, show a number of interesting differences to the perfect foresight case.

One is that at the outset investors briefly but sharply reduce consumption to permit a boost in capital investment, thereby supporting a faster increase in the capital stock. Loans also initially increase at a faster rate. The reason is that we have initialized both simulations at the state vector of the deterministic steady state. Under uncertainty however, investors would prefer higher capital and loan stocks even in the absence of realized negative shocks to $\eta$. This is because volatile bargaining power, by affecting incomes, increases consumption risk and thus lowers the expected utility of consumption. Investors can reduce their exposure to that risk by switching from consumption to holdings of capital and loans, which also offer utility but which are not equally affected by changes in bargaining power. In our baseline simulation the long-run value for workers' leverage is therefore around $90 \%$ rather than $64 \%$, and around a third of the increase in leverage observed over the pre-crisis period is due to convergence to this higher long-run value, with the other two thirds accounted for by the realized shocks to $\eta$. The relative effects of uncertainty versus realized $\eta$ on the capital stock are similar. Putting this differently, if our simulations under uncertainty were initialized at the stochastic rather than the deterministic steady state, the effects of realized bargaining power shocks on leverage and the capital stock over the first 30 years would be relatively smaller, but still very large in absolute terms.

Another interesting difference between the uncertainty and perfect foresight simulations concerns the longer-run behavior of capital and especially loans, which under uncertainty are noticeably lower at the 50-year horizon. The reason is that, at the very high levels of debt and capital reached by that time, the convexity of the crisis probability function assumes increasing importance. It implies that under uncertainty about future bargaining power the expected probability of a crisis is significantly higher, and therefore the willingness of investors to be exposed to such a crisis, through high stocks of loans and capital, is significantly lower. Of course in the very long run this picture is again reversed, as the perfect foresight economy returns to a leverage of $64 \%$, while the economy under uncertainty settles at a leverage of around $90 \%$.

\section{High Leverage - Aggravating Factors}

The baseline scenario has leverage increasing to around $135 \%$ by the time of the crisis $(125 \%$ under uncertainty), and remaining in the neighborhood of that value for decades afterwards, with a crisis probability hovering in the neighborhood of $3.5 \%$ for several decades $(2 \%$ under uncertainty). This outcome however depends on a number of aspects of the calibration of the 
model and of the specification of shocks, and changes to these can make the outcome for leverage worse or better. We begin by describing the factors aggravating crisis risks in this subsection, and in the next subsection we turn to possibilities for bringing down leverage.

In the baseline workers are partly compensated for their loss of bargaining power by the fact that investors invest part of their additional income in physical capital, which over time helps to raise the real wage. Figure 11 considers an alternative calibration where the marginal benefit to investors of doing so is reduced, so that more of their gains from higher bargaining power are either consumed or invested in loans. Specifically, by setting $\bar{k}=-33$ instead of $\bar{k}=-30$, capital accumulation is reduced by one third over the first 30 years, and output growth is reduced accordingly. ${ }^{10}$ One result is a further 2 percentage point increase in the consumption share of investors, as they consume instead of investing. The other is that leverage now reaches around $145 \%$ by the time of the crisis, and thereafter keeps growing to $175 \%$ by year 50 under perfect foresight, while it stays near $135 \%$ under uncertainty. Furthermore, the crisis itself is now characterized by a small increase rather than a decrease in leverage and in crisis probability. The longer-run crisis probabilities (almost $8 \%$ by year 50 under perfect foresight, 3\% under uncertainty) are far higher than in the baseline. The use of the additional income by investors is therefore a critical determinant of the sustainability of lower worker bargaining power. If a large share of the funds is invested productively, higher debt is more sustainable because it is supported by higher income. If instead the majority of the funds goes into investors' consumption, or into loan growth, in other words an increasing "financialization" of the economy, the system becomes increasingly unstable and prone to crises.

A second aspect of the baseline calibration that might be too optimistic is the rate at which workers' bargaining power is restored, after the initial period of declining bargaining power of 10 years. With $\rho=0.96,50 \%$ of the loss of bargaining power is reversed by year 27 . This was not an obvious feature of the pre-1929 and pre-2007 periods. Figure 12 therefore considers an alternative scenario with $\rho=0.99$, which is close to permanent, with the half-life of bargaining power equal to 80 years instead of 27 years. In this case the initial loss of bargaining power is assumed to be smaller, with $\eta$ dropping to 0.95 by year 10, rather than to 0.925 as in the baseline. Given the smaller initial drop in $\eta$, the increase in leverage and crisis probability by year 30 is of course smaller. But more interesting for our purposes is the fact that thereafter leverage keeps increasing further, including under uncertainty, and the crisis probability keeps climbing. It can in fact be shown that for this scenario the crisis probability does not peak until 50 years after the first crisis under uncertainty, and another 30 years later under perfect foresight. This illustrates a key concern. If workers see virtually no prospects of restoring their earnings potential even in the very long run, high leverage and high crisis risk become an almost permanent feature of the economy.

\footnotetext{
${ }^{10}$ It can therefore be seen that setting $\bar{k}$ much closer to zero would imply a massive and clearly implausible response of capital accumulation to income shocks.
} 
The third modification of the baseline that can give rise to higher crisis risk is a higher subsistence level of consumption. For most households it probably takes far less than a halving of consumption levels to arrive at what they perceive to be a disastrous event. A large number of households in modern economies, and not only the relatively poor, does in fact live paycheck to paycheck and would have to radically rearrange their affairs if faced with even a small drop in income. ${ }^{11}$ The scenario in Figure 13 therefore raises the subsistence level to $80 \%$ of initial steady-state consumption, but allows for that subsistence level to change gradually over time in response to realized consumption levels. Specifically, in the utility functions we replace the fixed $\tilde{c}_{\min }^{x}, x \in\{i, w\}$, by

$$
\tilde{c}_{t}^{x}=0.8 * \check{c}_{t}^{x}
$$

with

$$
\check{c}_{t}^{x}=\left(c_{t}^{x, a g g}\left(\check{c}_{t-1}^{x}\right)^{\psi}\right)^{\frac{1}{1+\psi}} .
$$

In the last two expressions $c_{t}^{x, a g g}$ is the aggregate per capita value of consumption of the respective household group, which is taken as given by the individual household and which equals $c_{t}^{x}$ in equilibrium, and $\check{c}_{t}^{x}$ is a moving average of past actual consumption, with the parameter $\psi$ determining the speed at which the moving average, and therefore the subsistence level, responds to changes in actual consumption. We set the moving-average parameter to $\psi=4$, which implies that the moving average reflects more than $90 \%$ of any permanent changes in consumption levels within approximately 4 years. Given (21), this version of our model has five continuous and one binary state variable, which makes application of the monotone map method computationally very costly. We therefore only report the perfect foresight simulation. We observe that under this specification households borrow much more aggressively than in the baseline to avoid a drop in consumption. As a result leverage reaches $155 \%$ at the time of the crisis, and close to $170 \%$ around year 40 , with a crisis probability that reaches $8 \%$ at its peak. However, under this specification workers are eventually willing to significantly reduce consumption, as their subsistence level comes down in the light of a prolonged experience of low consumption. Over the longer run this stabilizes leverage and avoids near explosive debt.

We have also explored the sensitivity of our results to alternative calibrations of the crisis probability function (9). We found that, even when the perceived probability of a crisis around year 30 and beyond is twice as large as in the baseline, the qualitative results are identical, and the quantitative results change very little. The reason is that a 2 percentage point increase in crisis probability, at a $10 \%$ default rate, adds at most around 10 to 20 basis points to real interest rates. This is small relative to the overall changes in real interest rates that the economy experiences in our scenarios.

\footnotetext{
${ }^{11}$ In a recent survey by the largest U.S. employment website (CareerBuilder (2010)), 77 percent of respondents report that they live paycheck to paycheck, up from 61 percent in 2009.
} 


\section{High Leverage - Solutions}

The currently much talked about deleveraging of households can in the present model take only two forms, a debt reduction, and ideally an "orderly" debt reduction, or an increase in workers' earnings to allow them to work their way out of debt over time. We address each of these in this subsection.

We first consider the option of an orderly debt reduction. What we have in mind here is a situation where a crisis and large-scale defaults have become unavoidable, but policy is used to limit the collateral damage in the real economy. Figure 14 illustrates the case where the destruction of physical capital at crisis time only equals $1 \%$ instead of $10 \%$, leaving all other aspects of the baseline calibration unchanged. The main difference to the baseline is that in this case the debt reduction is not accompanied by a significant income reduction, as the real wage drops very little. As a result, leverage drops by 13.5 percentage points, compared to 3 percentage points in the baseline. Minimizing spillovers from the financial to the real sector

during a widespread debt restructuring to deal with excessive leverage is therefore critical to the success of that restructuring.

In this context it should be mentioned that a financial sector bailout such as the one recently performed in the United States does not represent a debt restructuring in the sense of Figure 14. A bailout principally benefits the creditors of financial institutions, in other words the investors of our model, by compensating them for loan losses. The financing for such a bailout however comes from higher future general tax revenue that will be used to service higher government debt, and will therefore fall to a very significant extent on workers. The proper definition of workers' indebtedness in an extended model including the fiscal authorities would then include the present discounted value of future taxes. In such a world the beneficial effects of debt default on leverage would be mostly offset by the negative effects of higher future taxes.

Figure 15 illustrates the alternative to a debt restructuring, an increase in workers' earnings through a restoration of their original bargaining power. In this case the evolution of the economy is identical to the baseline until period 30, but at that time a program is implemented whereby workers' bargaining power immediately and permanently returns to $\eta=1$. The assumption is that this is sufficient to head off a crisis event. The first result is an upward jump in the real wage to about $4 \%$ above its value in period 0 , due to the now much higher capital stock. Leverage drops by 8 percentage points on impact (both under perfect foresight and under uncertainty), but this is now not due to a lower, restructured loan stock, but rather to a higher income level, which is of course helped by the fact that this turn of events is assumed to head off a collapse in capital and output. The main difference to Figure 14 however is observed following period 30, where under a loan restructuring leverage and default probability resume an upward trajectory for several additional decades, while under the bargaining power solution both immediately go onto a declining path. By year 50 leverage is 
around 20 percentage points lower under the bargaining power solution than under the loan restructuring solution. For long-run sustainability a permanent flow adjustment, giving workers the means to repay their obligations over time, is therefore much more successful than a stock adjustment, unless the latter is extremely large.

Any success in reducing income inequality could therefore be very useful in order to reduce the likelihood of future crises. Clearly however this will not be easy to achieve, as candidate policies are subject to many difficulties. For example, downward pressure on wages is driven by powerful international forces such as competition from China, while a switch from labor to capital income taxes might drive investment to other jurisdictions. But a switch from labor income taxes to taxes on economic rents, including on land, natural resources and financial sector rents, is not subject to the same problem. And as far as strengthening the bargaining powers to workers is concerned, the difficulties of doing so have to be weighed against the potentially disastrous consequences of further deep financial and real crises if current trends continue.

\section{E. Further Discussion}

Our model has been kept deliberately simple, first in order to clearly identify the key transmission channel from higher income inequality to higher leverage to a higher probability of crises, and second for computational reasons, as a higher number of shocks or endogenous state variables would quickly make the monotone map method impractical. It is nevertheless useful to close this section by commenting on how various additions to the model could improve details of its predictions.

By adding an open economy dimension, with net foreign assets as an additional state variable and foreign savings preferences as an additional shock, the model would be better able to replicate the fact that the United States experienced a consumption boom over much of the period of interest, much of which was facilitated by the availability of foreign savings.

The addition of contractionary technology and investment demand shocks would generate the large and persistent post-crisis reduction in investment observed in the United States after 2007.

Finally, the addition of a shock to workers' labor supply would help to address an important issue raised by Reich (2010), who emphasizes that in the United States households faced with higher income inequality have employed two other important coping mechanism apart from higher borrowing, namely higher female labor force participation and longer hours. This allowed them to replace some of the lost income, and therefore to limit the amount of additional borrowing. 


\section{Conclusions}

This paper has presented stylized facts and a theoretical framework that explore the nexus between increases in the income advantage enjoyed by high income households, higher debt leverage among poor and middle income households, and vulnerability to financial crises. This nexus was prominent prior to both the Great Depression and the recent crisis. In our model it arises as a result of increases in the bargaining power of high income households. The key mechanism, reflected in a rapid growth in the size of the financial sector, is the recycling of part of the additional income gained by high income households back to the rest of the population by way of loans, thereby allowing the latter to sustain consumption levels, at least for a while. But without the prospect of a recovery in the incomes of poor and middle income households over a reasonable time horizon, the inevitable result is that loans keep growing, and therefore so does leverage and the probability of a major crisis that, in the real world, typically also has severe implications for the real economy. More importantly, unless loan defaults in a crisis are extremely large by historical standards, and unless the accompanying real contraction is very small, the effect on leverage and therefore on the probability of a further crisis is quite limited. By contrast, restoration of poor and middle income households' bargaining power can be very effective, leading to the prospect of a sustained reduction in leverage that should reduce the probability of a further crisis.

The framework we have presented uses a closed economy setting. In future work we aim to extend this to an open economy. It is clear that the same mechanism presented in this paper, namely the increase in lending by high income households in the country that is subject to a bargaining power shock favoring high income households, would then extend not just to domestic poor and middle income households, but also to foreign households. The counterpart of this capital account surplus in the foreign country would of course be an increase in its current account deficit. In other words, this provides a potential mechanism to explain global current account imbalances triggered by increasing income inequality in surplus countries. 


\section{REFERENCES}

Armstrong, J., Black, R., Laxton, D. and Rose, D. (1998), “A Robust Method for Simulating Forward-Looking Models", Journal of Economic Dynamics and Control, 22, 489-501.

Barro, R., (2006), "Rare Disasters and Asset Markets in the Twentieth Century", Quarterly Journal of Economics, 121(3), 823-866.

Blanchard, O. and Giavazzi, F. (2003), "Macroeconomic Effects Of Regulation And Deregulation In Goods And Labor Markets", Quarterly Journal of Economics, 118(3), 879-907.

Borjas, G. and Ramey, V. (1995), "Foreign Competition, Market Power and Wage Inequality", Quarterly Journal of Economics, 110(4), 1075-1110.

Bradbury, K. and Katz, J. (2002), "Are Lifetime Incomes Growing More Unequal? Looking at New Evidence on Family Income Mobility", Regional Review, 12(4).

Card, D., Lemieux, T., and Riddell, D. (2004), "Unions and Wage Inequality", Journal of Labor Market Research, 25(4), 520-562.

CareerBuilder (2010), "One-in-Five Workers Have Trouble Making Ends Meet as More Indicate They Live Paycheck to Paycheck", available at http://www.careerbuilder.com.

Carroll, C.D. (2000), “Why Do the Rich Save So Much?", in Joel B. Slemrod, Ed., Does Atlas Shrug? The Economic Consequences of Taxing the Rich, Cambridge, MA: Harvard University Press.

Coleman, J. (1991), "Equilibrium in a Production Economy with an Income Tax", Econometrica, 59, 1091-1104.

Davig, T. (2004), "Regime-Switching Debt and Taxation", Journal of Monetary Economics, 51, 837-859.

Davig, T. and Leeper, E. (2006), "Fluctuating Macro Policies and the Fiscal Theory", NBER Macroeconomics Annual, 21, 247-298.

Davig, T. and Leeper, E. (2007), "Generalizing the Taylor Principle", American Economic Review, 97(3), 607-635.

Davig, T., Leeper, E. and Walker, T. (2010), "Unfunded Liabilities and Uncertain Fiscal Financing", Journal of Monetary Economics (forthcoming). 
Diamond, D. and Dybvig, P. (1983), "Bank Runs, Deposit Insurance, and Liquidity”, Journal of Political Economy, 91(3), 401-419.

Dynan, K., Skinner, J. and Zeldes, S. (2004), “Do the Rich Save More?”, Journal of Political Economy, 112(2), 397-444.

Heathcote,J., Perri, F. and Violante, G.L. (2010), “Unequal We Stand: An Empirical Analysis of Economic Inequality in the United States: 1967-2006", Review of Economic Dynamics, 13(1), 15-51.

International Monetary Fund (2009), "Crises and Recovery", Chapter 3 in World Economic Outlook, April 2009.

Juillard, M., D. Laxton, H. Pioro and P. McAdam (1998), “An Algorithm Competition: First-Order Techniques Versus Newton-Based Techniques”, Journal of Economic Dynamics and Control, 22(8-9), 1291-1318.

Iacoviello, M. (2005), "House Prices, Borrowing Constraints, and Monetary Policy in the Business Cycle”, American Economic Review, 95(3), 739-764.

Iacoviello, M. (2008), “Household Debt and Income Inequality, 1963-2003”, Journal of Money, Credit and Banking, 40(5), 929-965.

Keys, B.J., Mukherjee, T., Seru, A. and Vig, V. (2010), "Did Securitization Lead to Lax Screening? Evidence from Subprime Loans", Quarterly Journal of Economics, 125(1), 307-62.

Kopczuk, W. (2007), "Bequest and Tax Planning: Evidence from Estate Tax Returns", Quarterly Journal of Economics, 122(4), 1801-1854.

Kopczuk, W., Saez, E., and Song, J., (2010), Earnings Inequality and Mobility in the United States: Evidence from Social Security Data since 1937, Quarterly Journal of Economics, 125(1), 91-128

Krueger, D. and Perri, F. (2006), "Does Income Inequality Lead to Consumption Inequality? Evidence and Theory", Review of Economic Studies, 73(1), 163-193.

Lemieux, T. (2006), "Post-Secondary Education and Increasing Wage Inequality", American Economic Review, 96(2), 195-199.

Lemieux, T., MacLeod, B. and Parent, D. (2009), "Performance Pay and Wage Inequality", Quarterly Journal of Economics, 124(1), 1-49.

Obstfeld, M. and Rogoff, K. (2009), “Global Imbalances and the Financial Crisis: Products 
of Common Causes", Working Paper, UC Berkeley and Harvard University.

Piketty, T. and Saez, E. (2003), "Income Inequality in the United States, 1913-1998", Quarterly Journal of Economics, 118, 1-39.

Philippon, T. (2008), “The Evolution of the U.S. Financial Industry from 1860 to 2007”, Working Paper, New York University.

Piketty, T. (2010), “On the Long-Run Evolution of Inheritance: France 1820-2050”, Working Paper, Paris School of Economics.

Rajan, R. (2010), Fault Lines: How Hidden Fractures Still Threaten the World Economy, Princeton: Princeton University Press.

Rancière, R., Tornell, A. and Westermann, F. (2008), "Systemic Crises and Growth", Quarterly Journal of Economics, 123(1), 359-406.

Reich, R. (2010), Aftershock: The Next Economy and America's Future, New York: Random House.

Reiter, M. (2004), "Do the Rich Save too Much? How to Explain the Top Tail of the Wealth Distribution", Working Paper, Universitat Pompeu Fabra.

Roberts, P.C. (2010), How the Economy Was Lost, AK Press.

Schneider, M. and Tornell, A. (2004), "Balance Sheet Effects, Bailout Guarantees and Financial Crises", Review of Economic Studies, 71, 883-913.

Taylor, J.B. (2009), Getting Off Track: How Government Actions and Interventions Caused, Prolonged, and Worsened the Financial Crisis, Hoover Institution Press. 
Figure 1. Income Inequality and Household Leverage

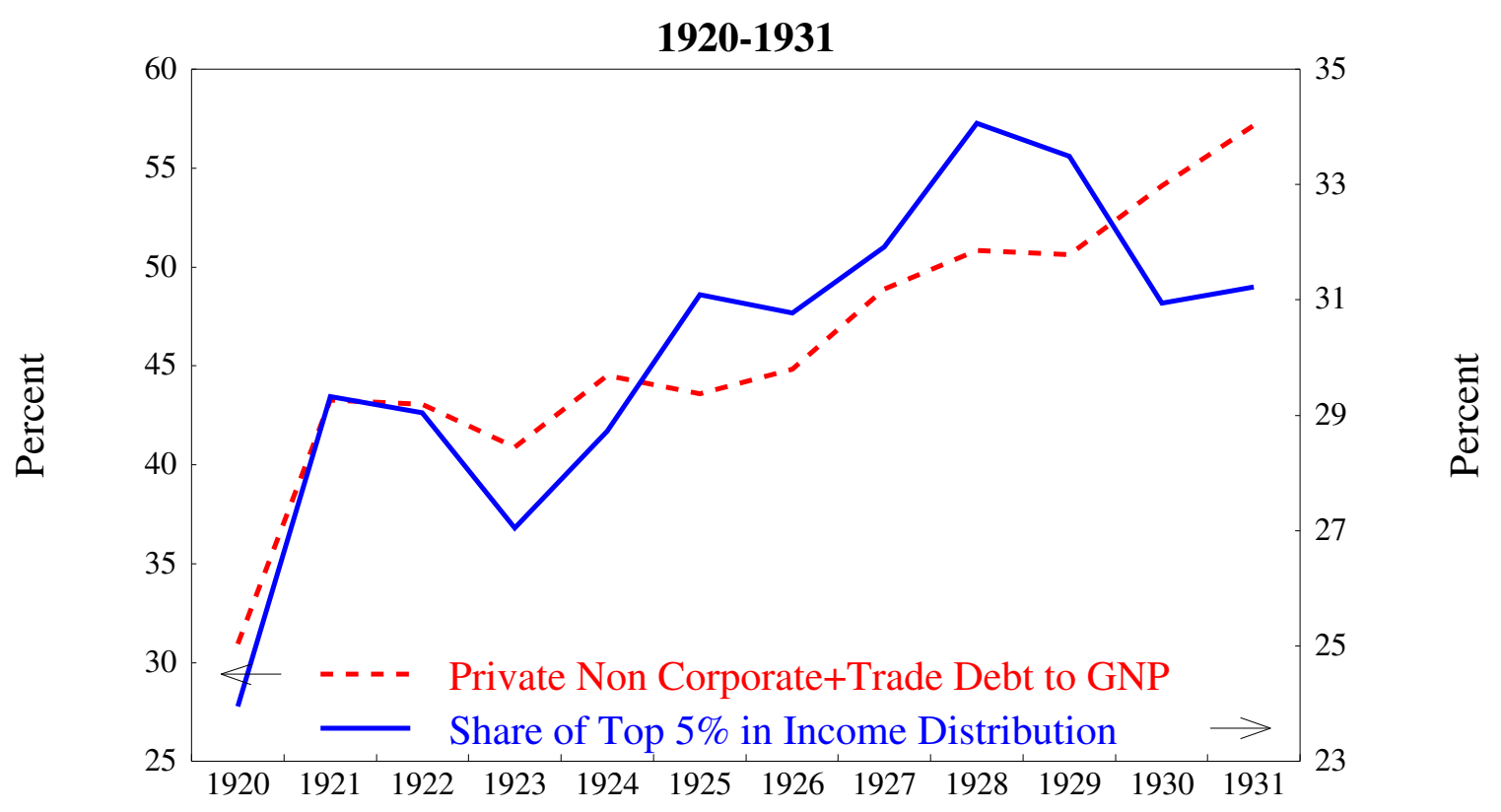

Source: Statistical Abstract of the United States, U.S. Department of Commerce.

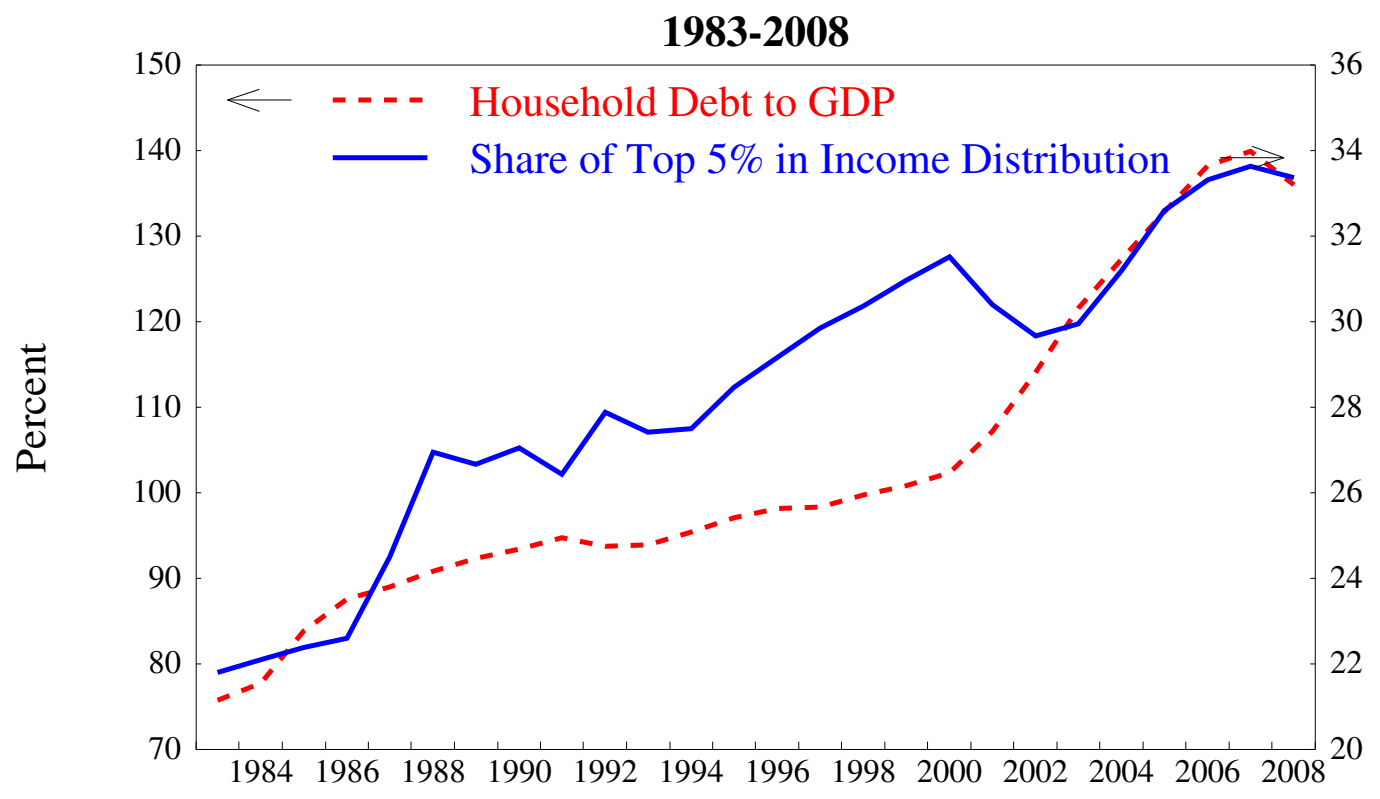

Sources: Income shares from Piketty and Saez (2003, updated). Income excludes capital gains. Debt-to-income ratios from Flows of Funds database, Federal Reserve Board. Income excludes capital gains. 
Figure 2. Real Income Inequality
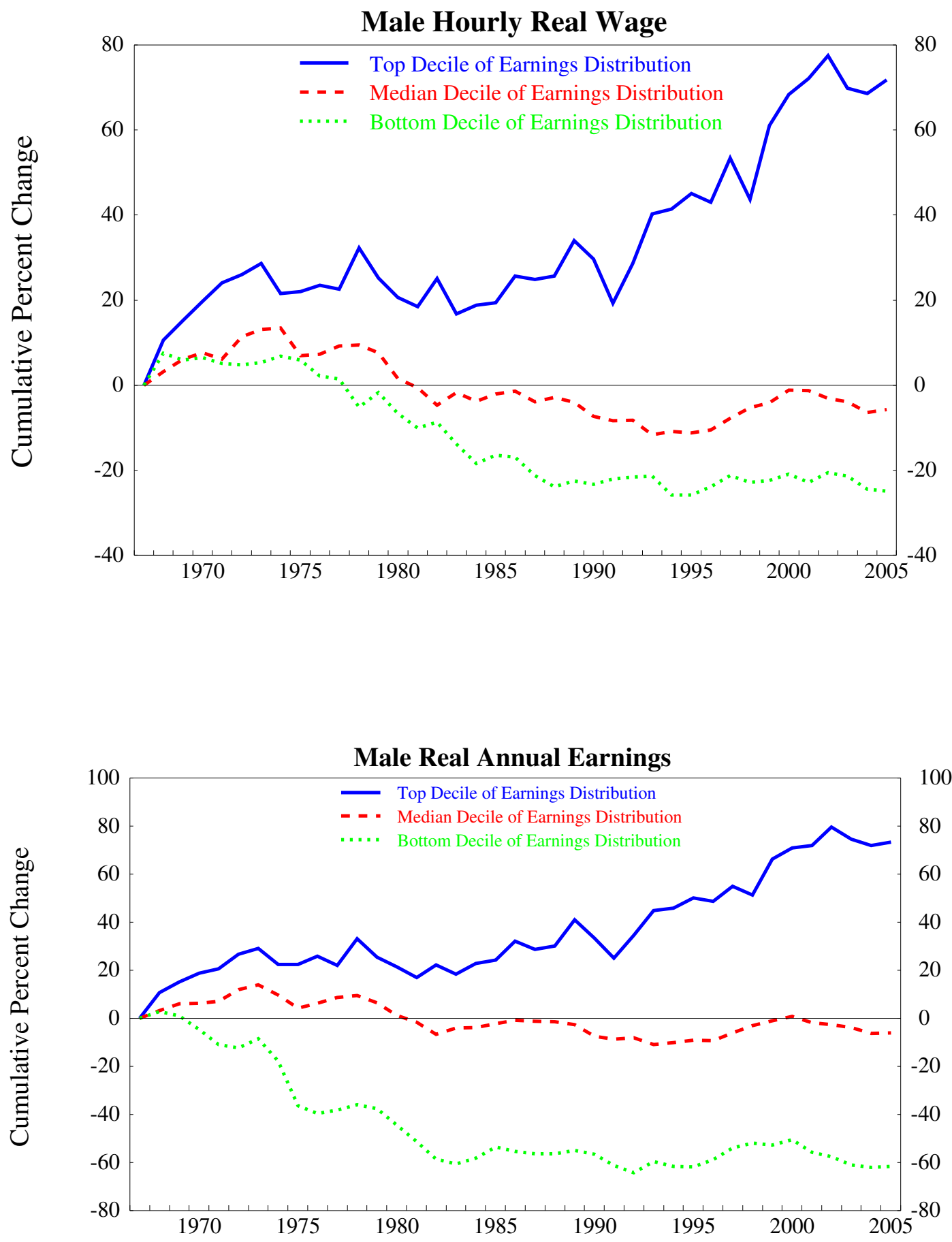

Source: Heathcote, Perri and Violante (2010), based on micro-level data from the U.S. Consumer Population Survey. Male annual earnings includes labor income plus two-thirds of self-employment income. Male hourly wages are computed as male annual earnings divided by annual hours. The price deflator used is the Bureau of Labor Statistics CPI-U series, all items. 
Figure 3. Income Inequality and Consumption Inequality

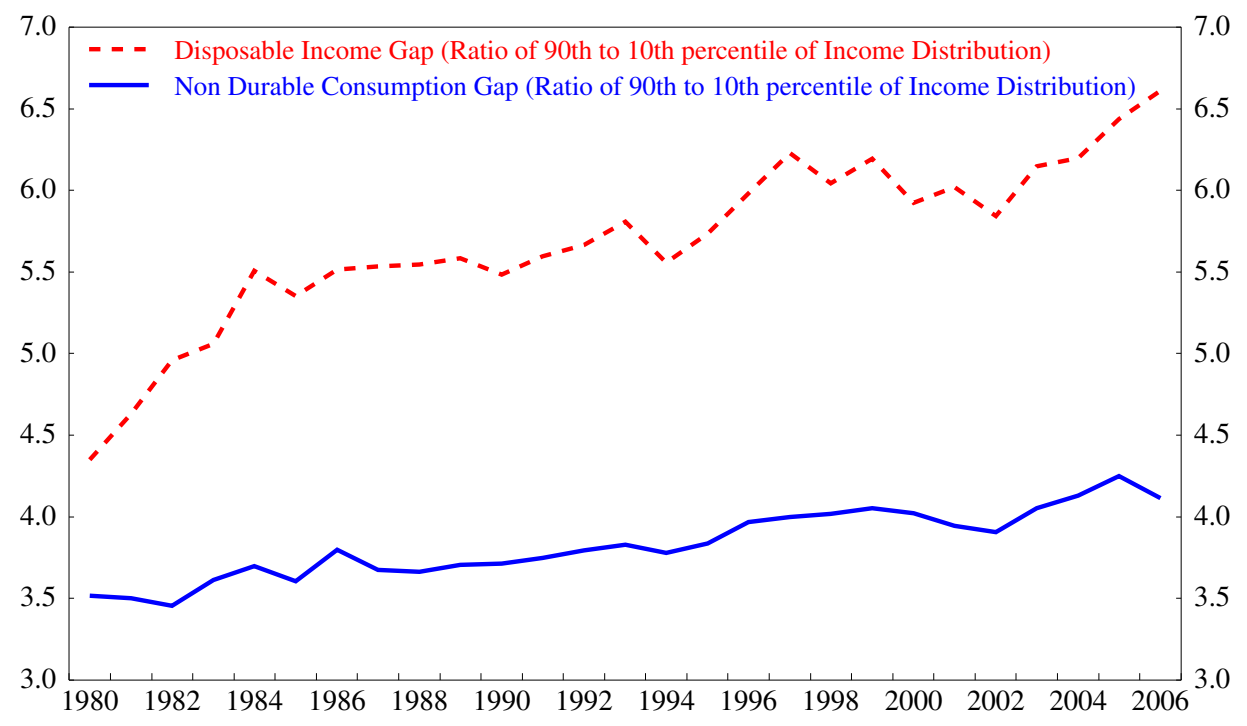

Source: Heathcote, Perri and Violante (2010), based on micro-level data from the U.S. Consumer Population Survey. Income corresponds to disposable income, and consumption to non-durable consumption expenditures.

Figure 4. The Variance of Annual, Permanent, and Transitory (log) Earnings

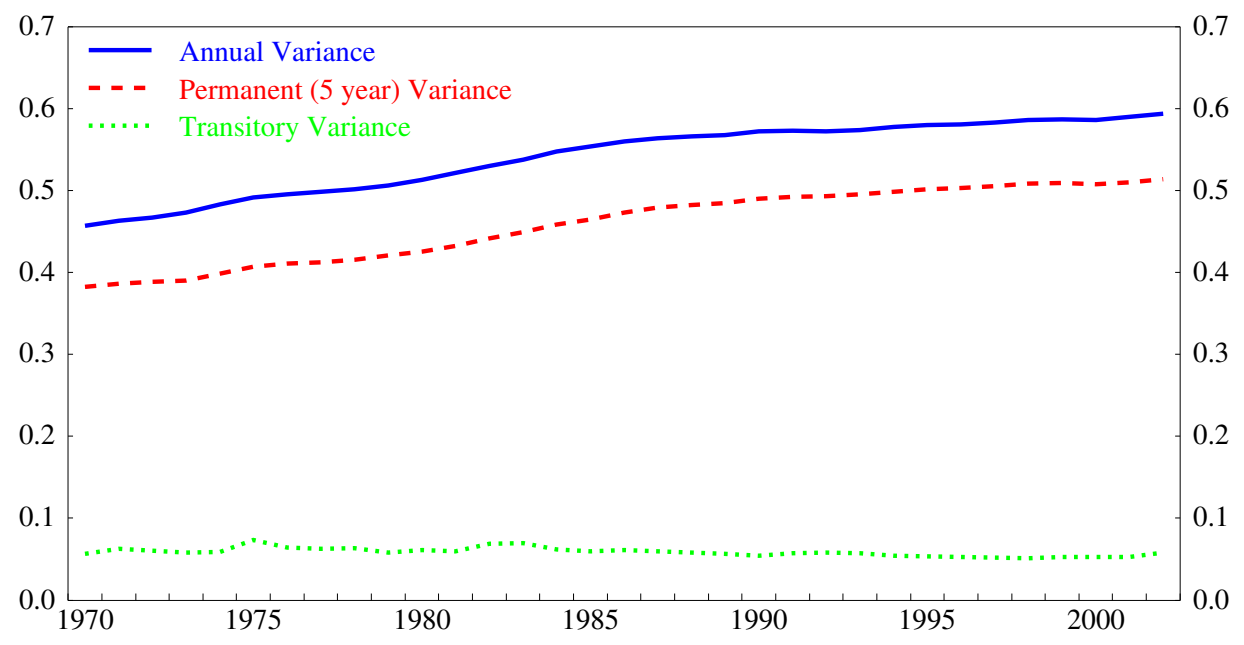

Source: Kopczuk, Saez and Jong (2010), based on Social Security Administration longitudinal earnings micro data. Earnings include all wages or self-employement earnings subject to social security taxes. The transitory variance is defined as the variance of the difference between $(\log )$ annual earnings and $(\log )$ five-year average earnings. 


\section{Figure 5. Debt to Income Ratios}

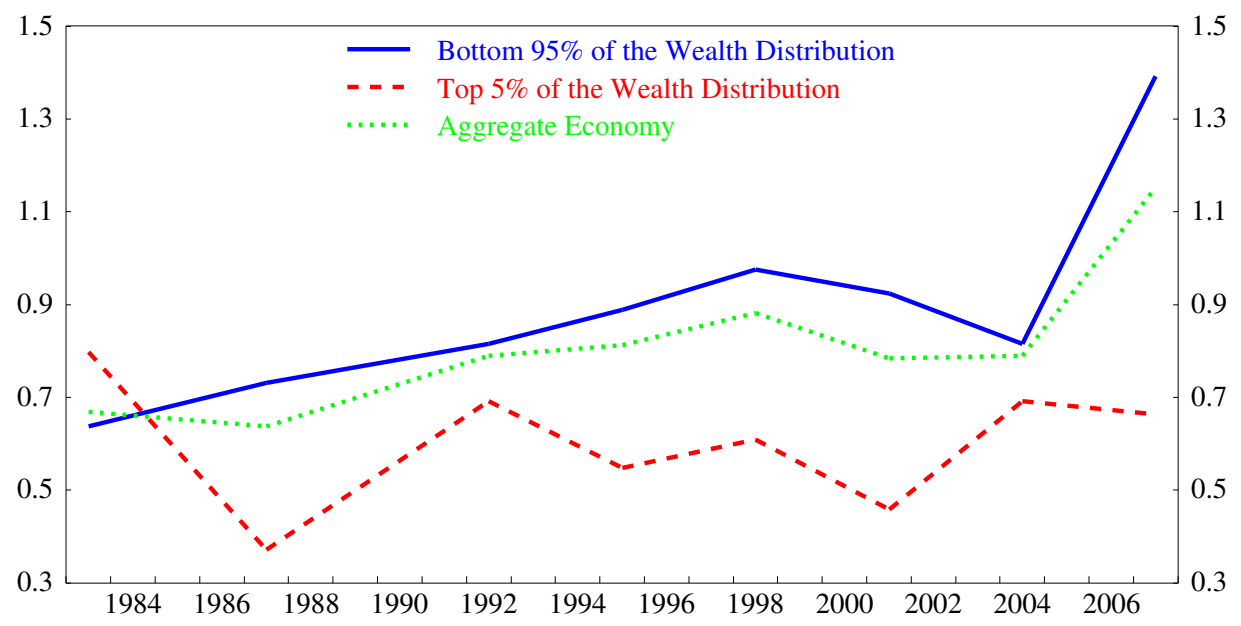

Source: Survey of Consumer Finance (triennal), 1983-2007. Debt corresponds to the shock of all outstanding household debt liabilities. Income corresponds to annual income before taxes, including capital gains and transfers, in the year preceding the survey.

Figure 6. The Size of the U.S. Financial Sector

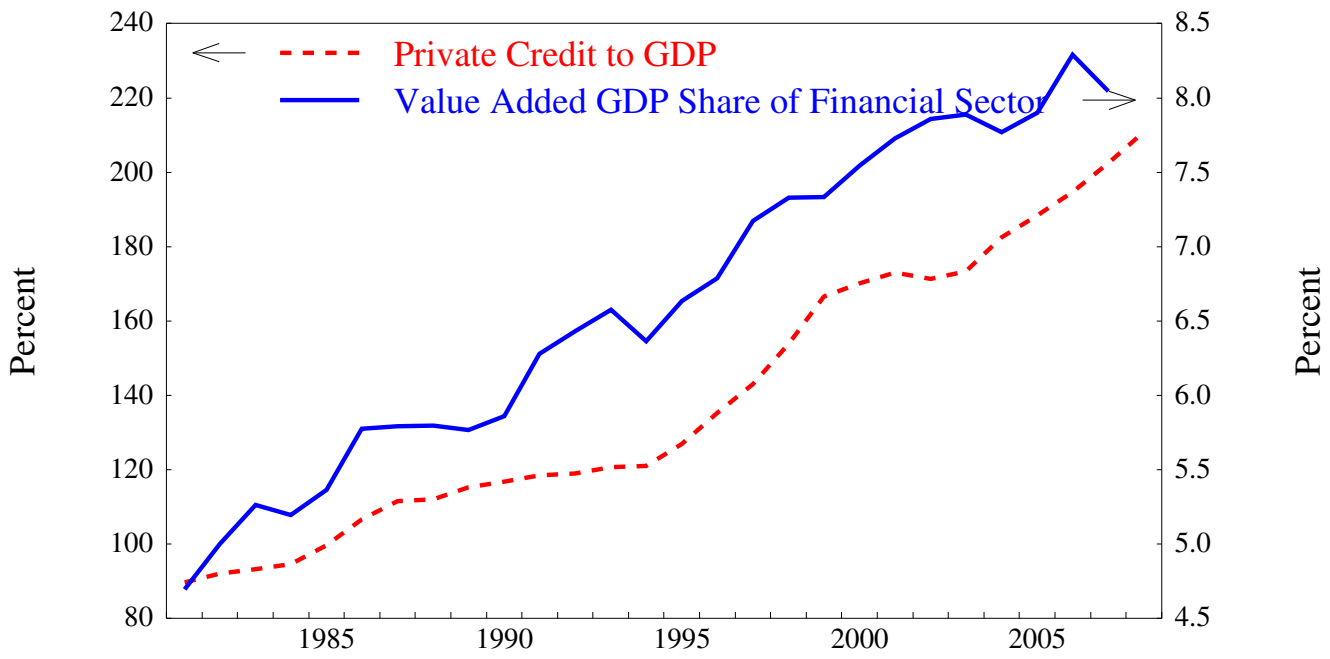

Sources: Private Credit to GDP from World Bank Financial Structure Database (real private credit by deposit banks and other financial institutions, relative to GDP). Value Added GDP Share of Financial Sector from Philippon (2008). 
Figure 7. Mortgage Debt and Subprime Borrowing

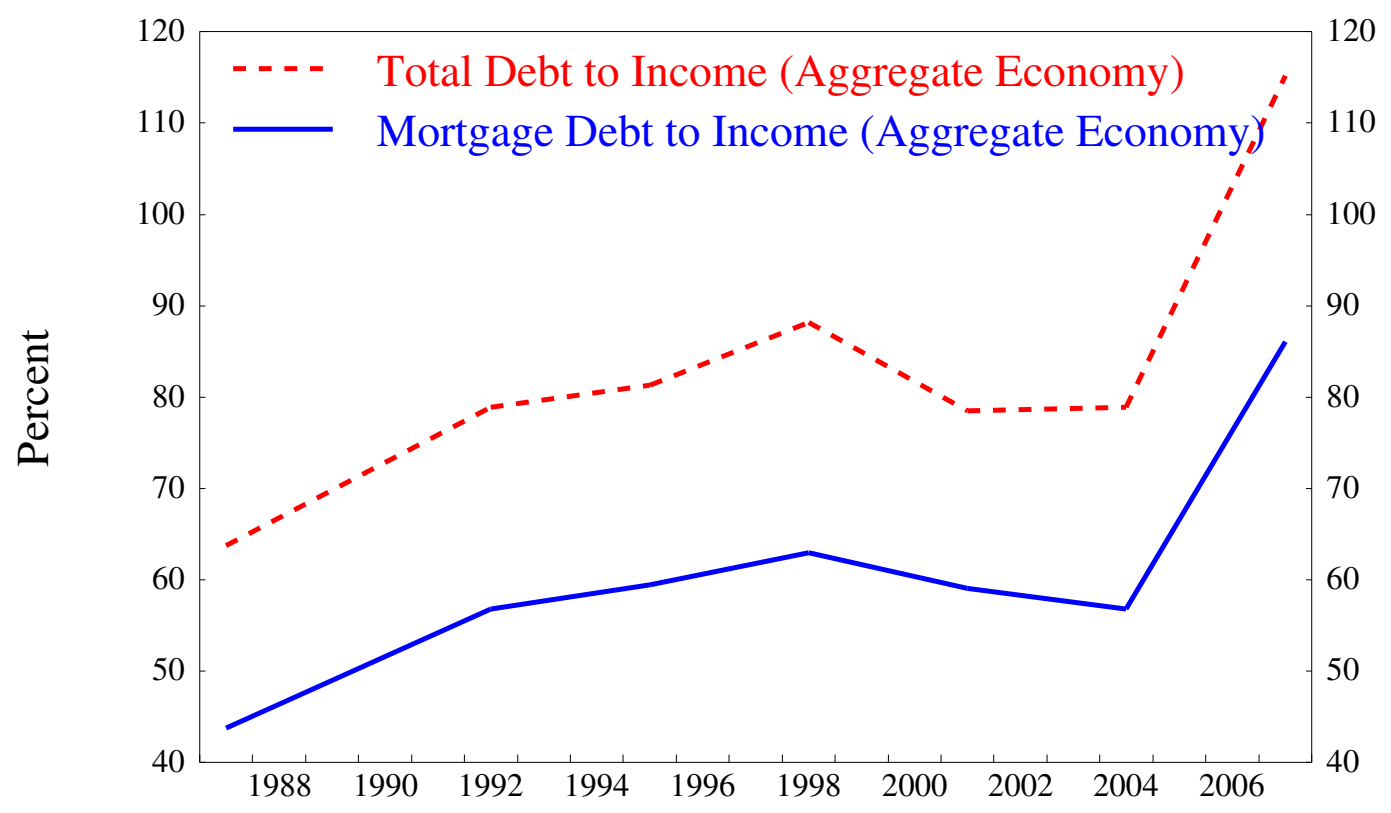

Source: Survey of Consumer Finance. Mortgage Debt corresponds to the amount outstanding on mortgages and home equity lines of credit secured by principal residences.

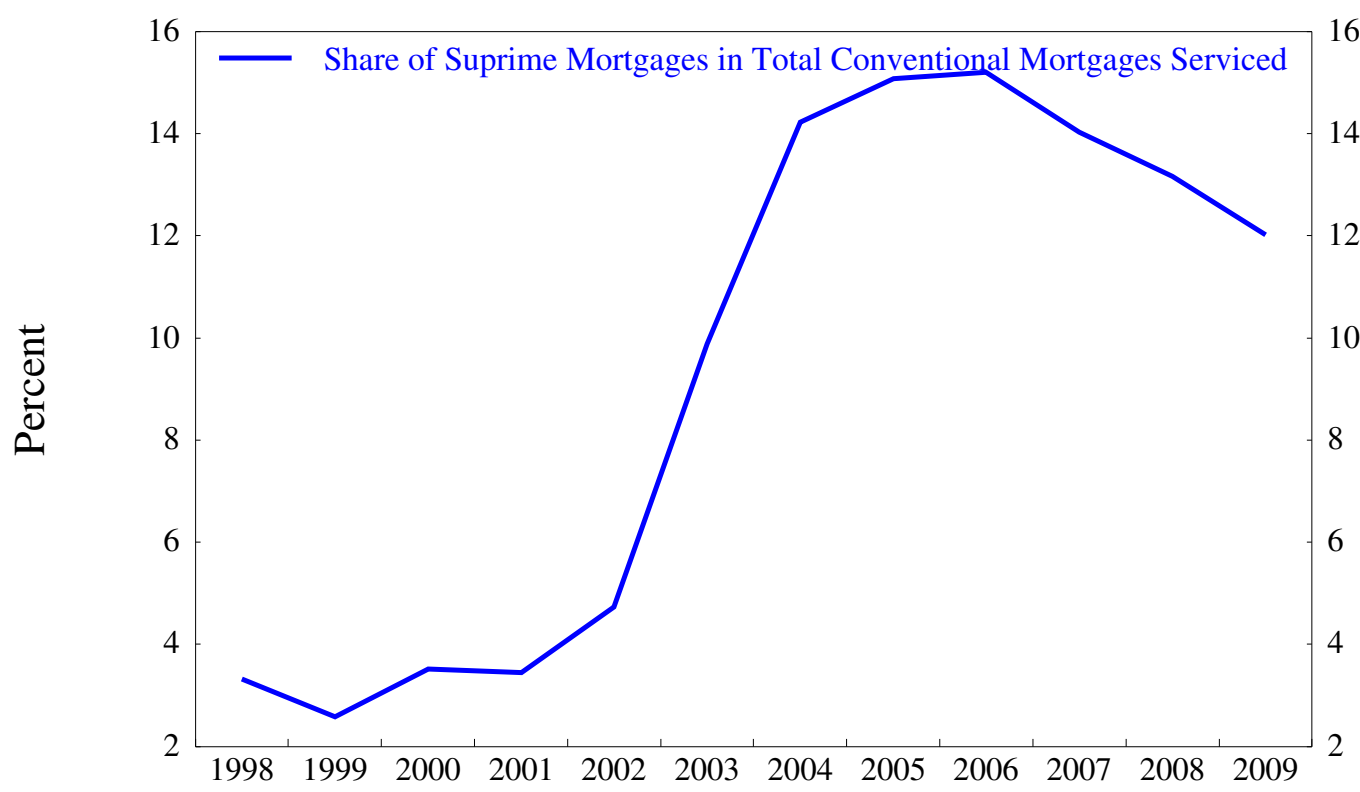

Source: Mortgage Bankers Association. Share of conformable subrime loans in the total numbers of mortgage loans serviced. 
Figure 8. Mortgage Default - Share of Past Due Loans

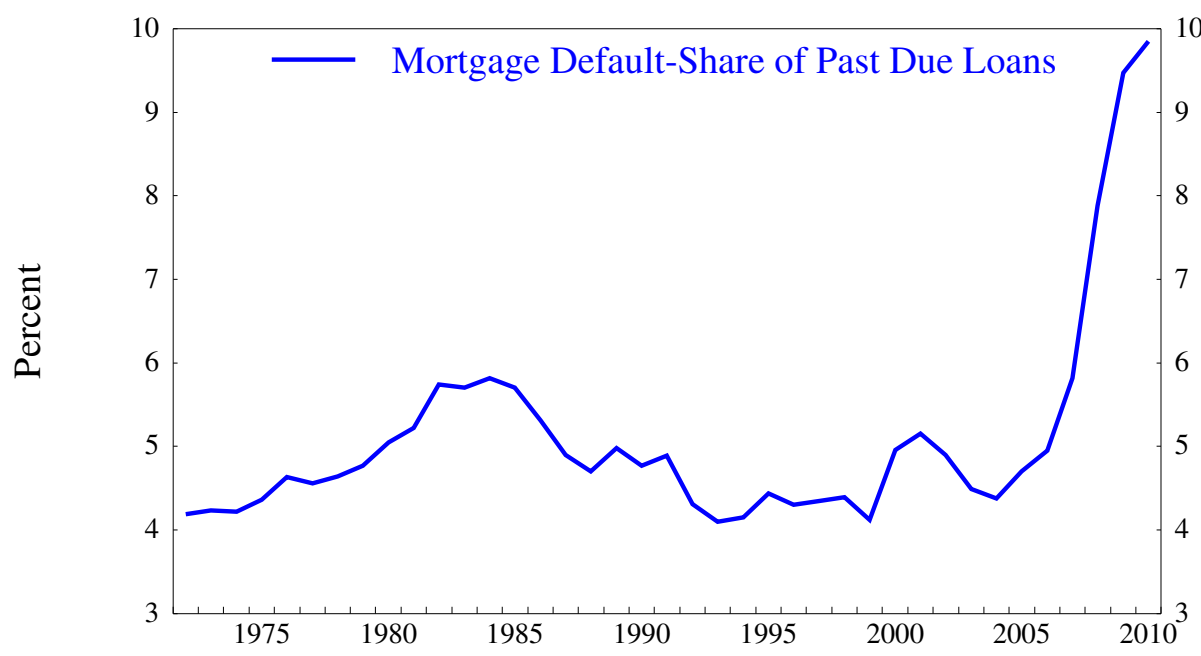

苂

Source: Haver Analytics, using data from Mortgage Bankers Association Delinquency Survey.

Figure 9. Leverage and Crisis Probability in the Model

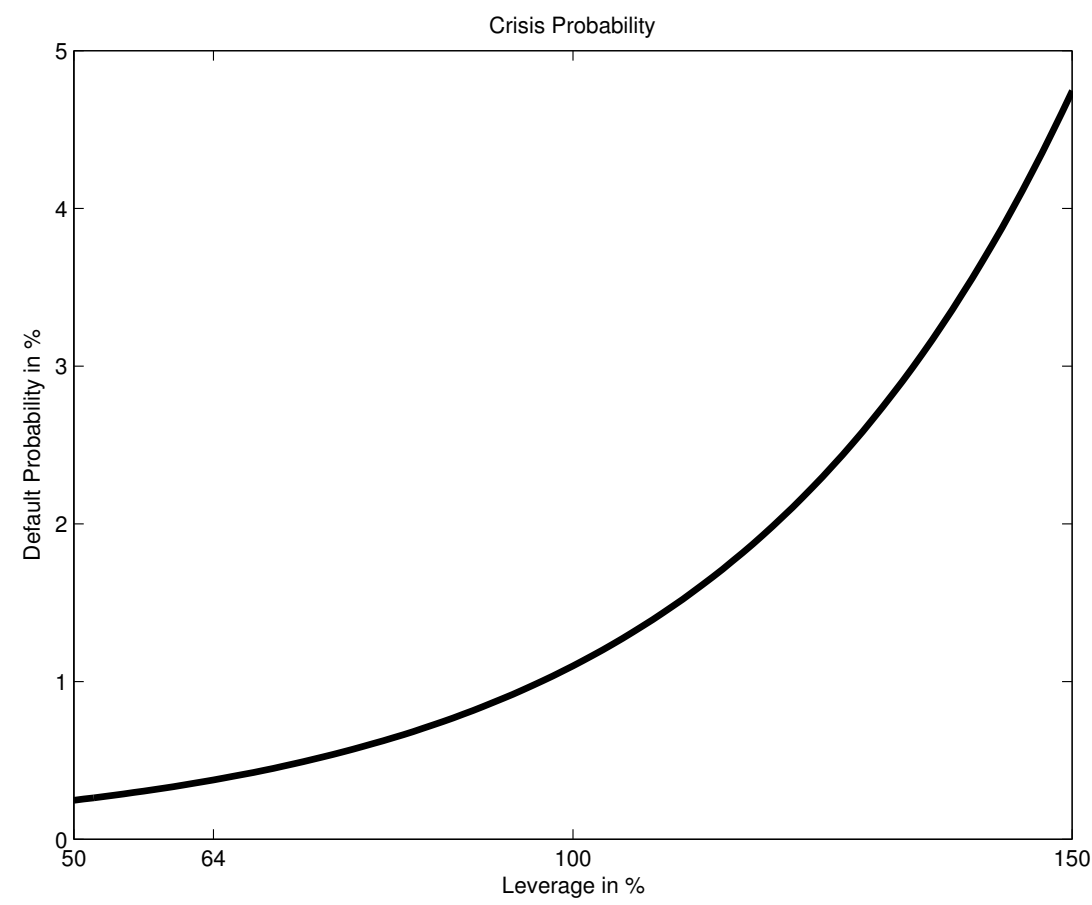


Figure 10. Baseline Scenario
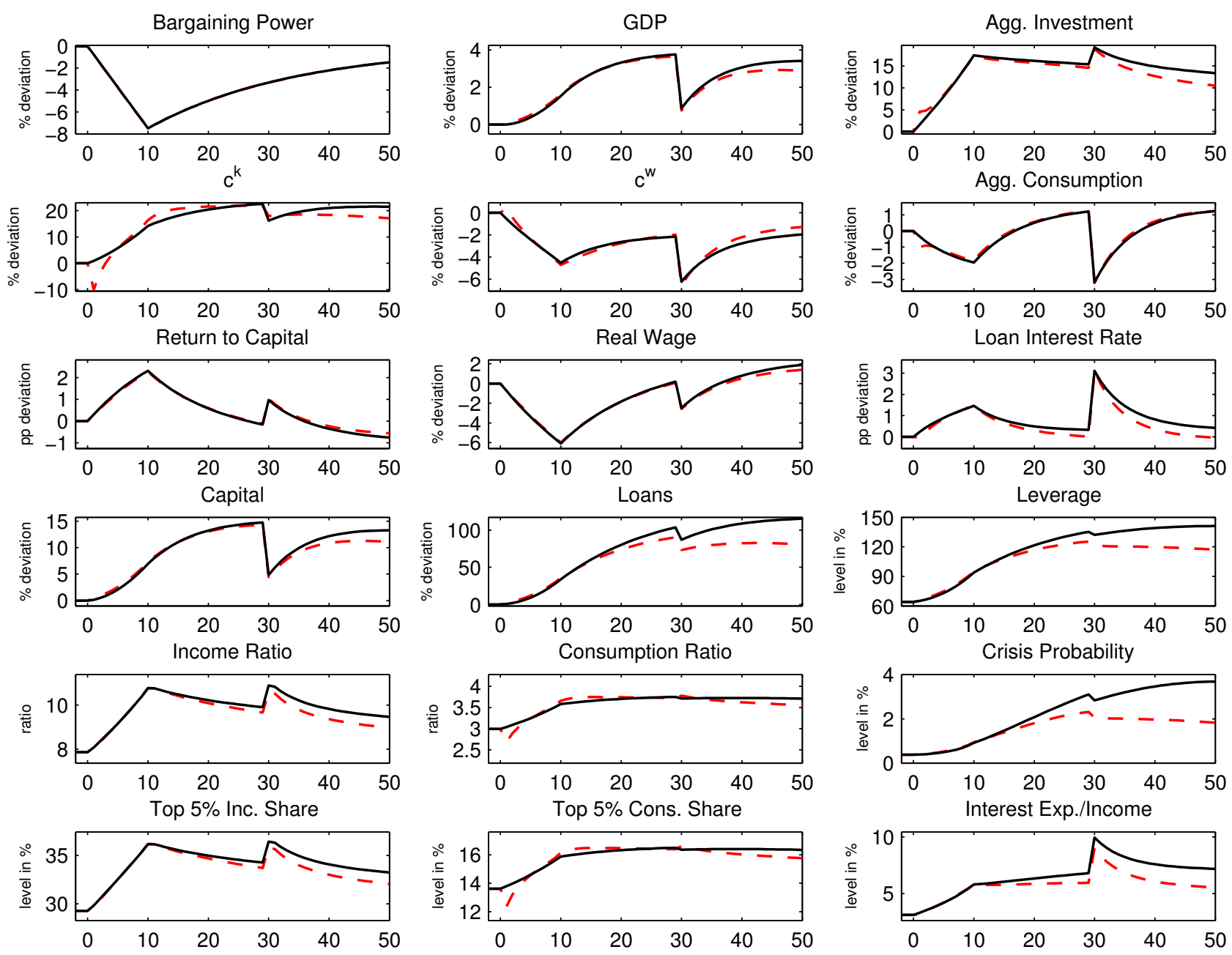
Figure 11. Less Capital Investment
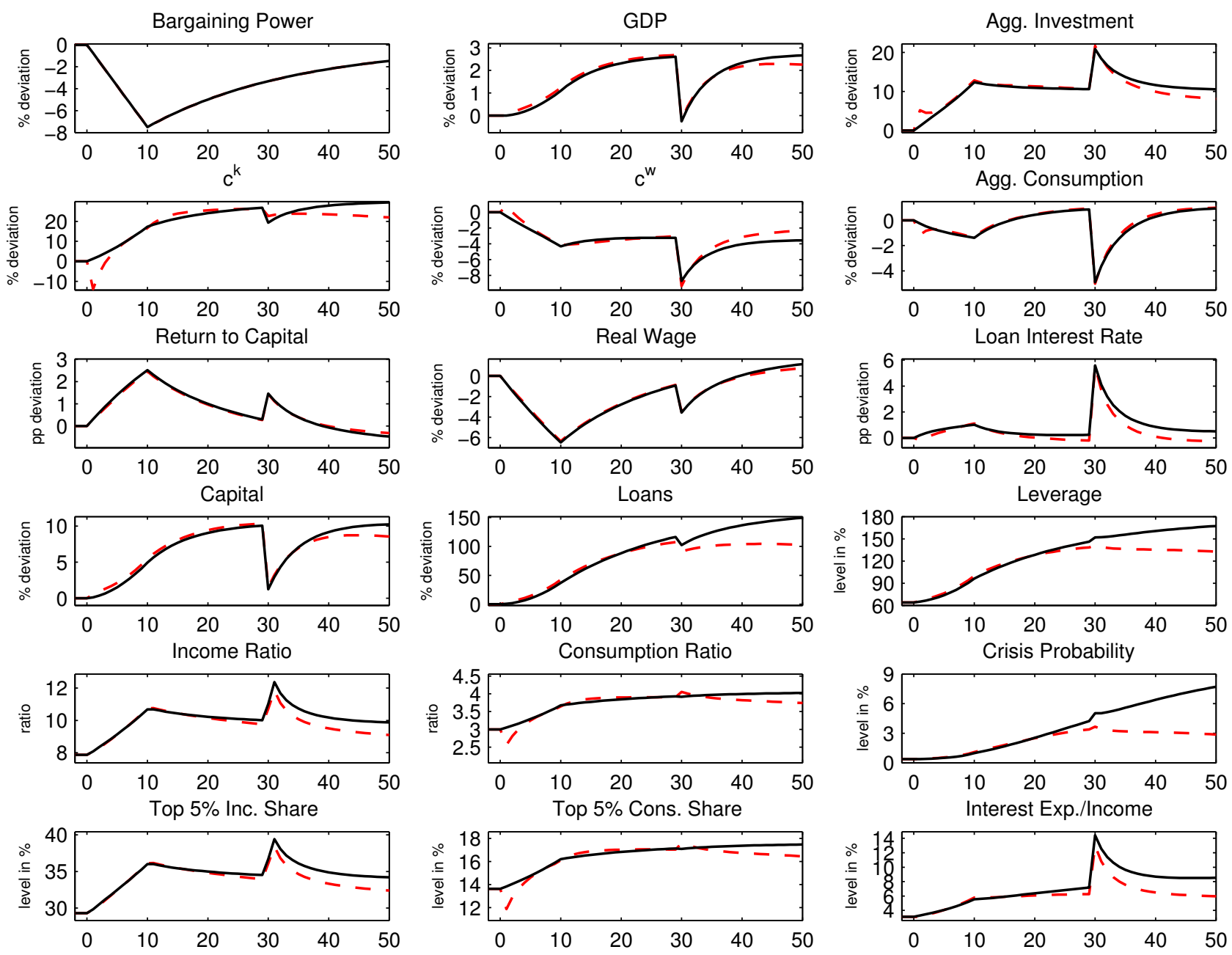
Figure 12. Nearly Permanent Change in Bargaining Power
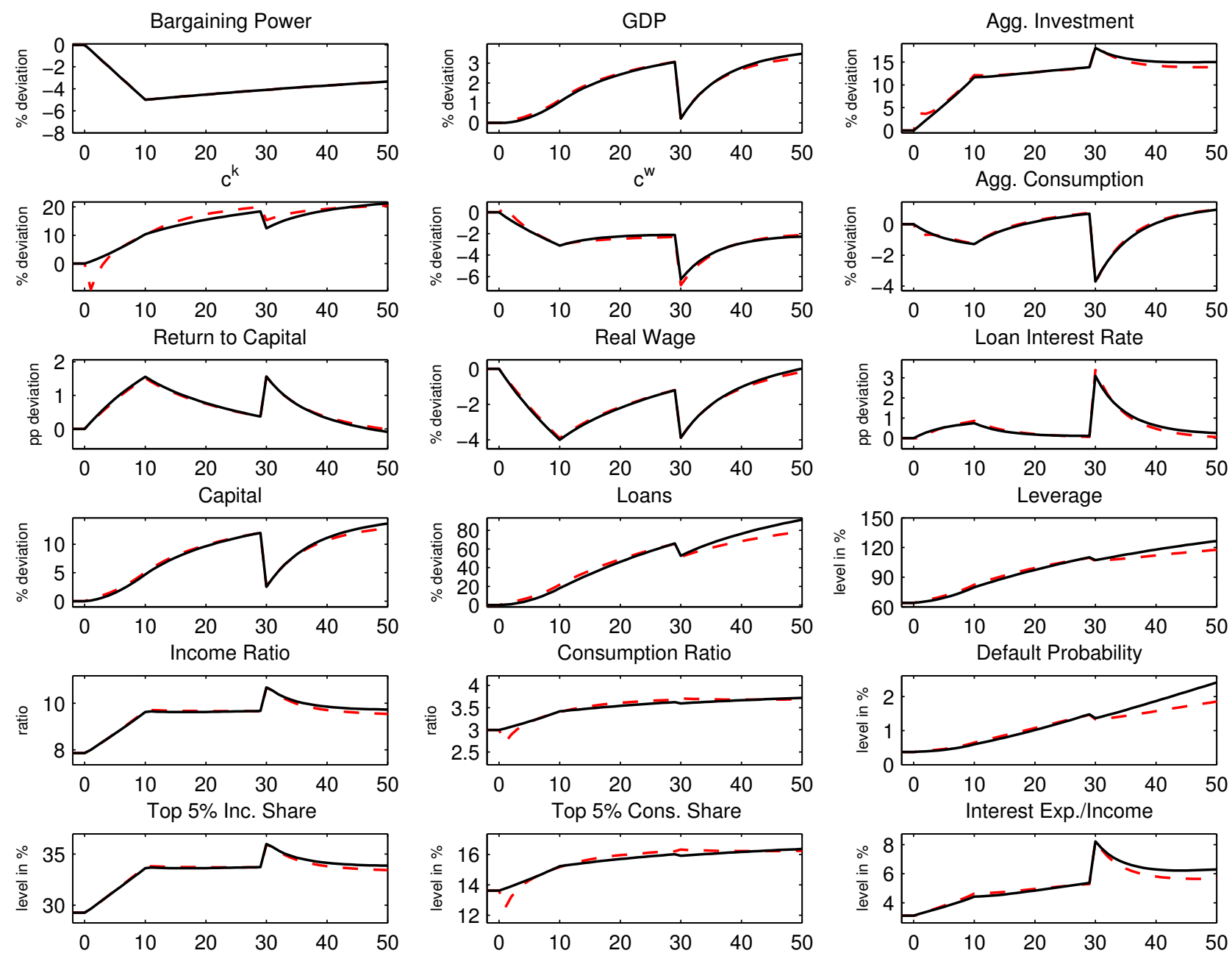
Figure 13. High Variable instead of Low Fixed Subsistence Consumption
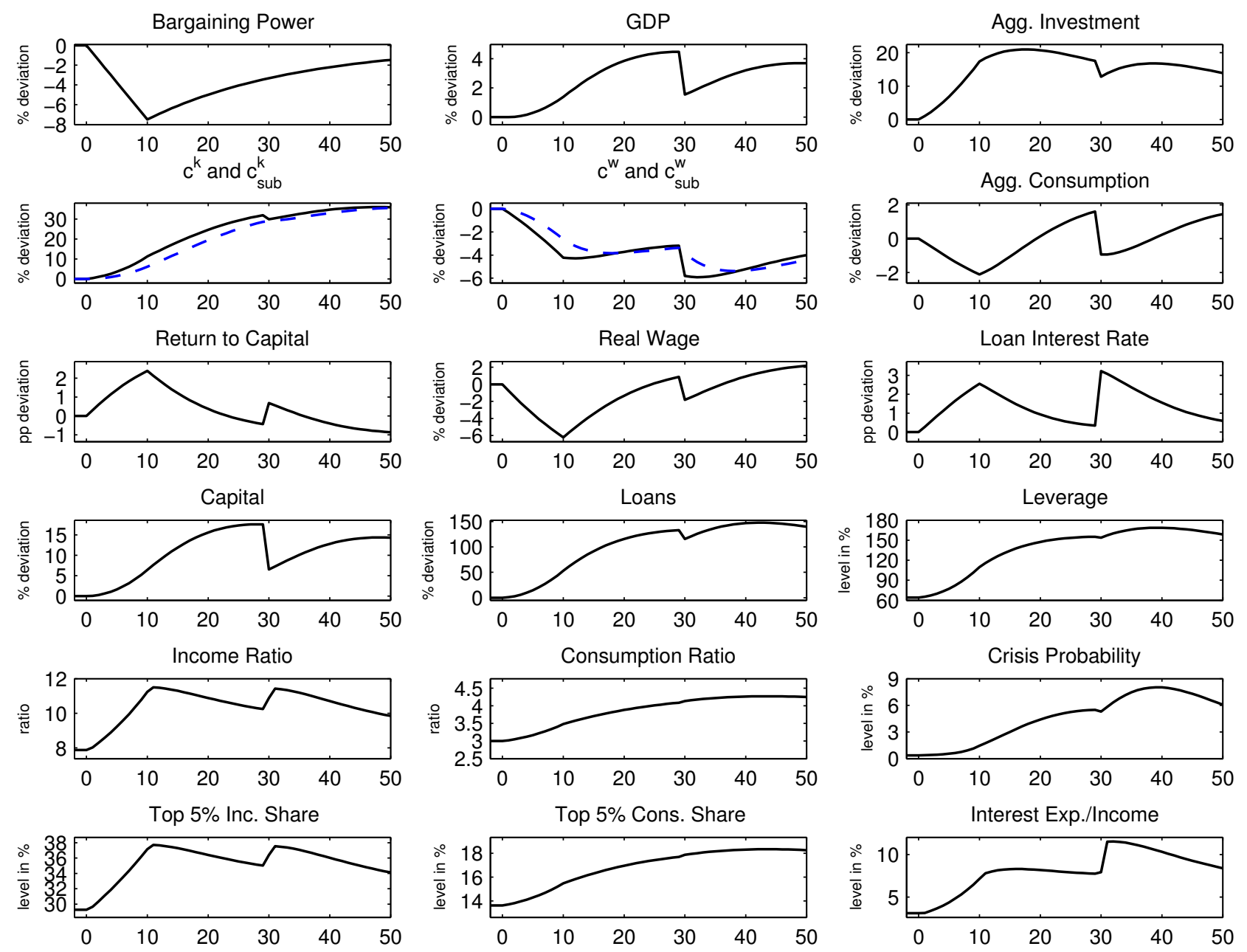
Figure 14. Orderly Debt Restructuring
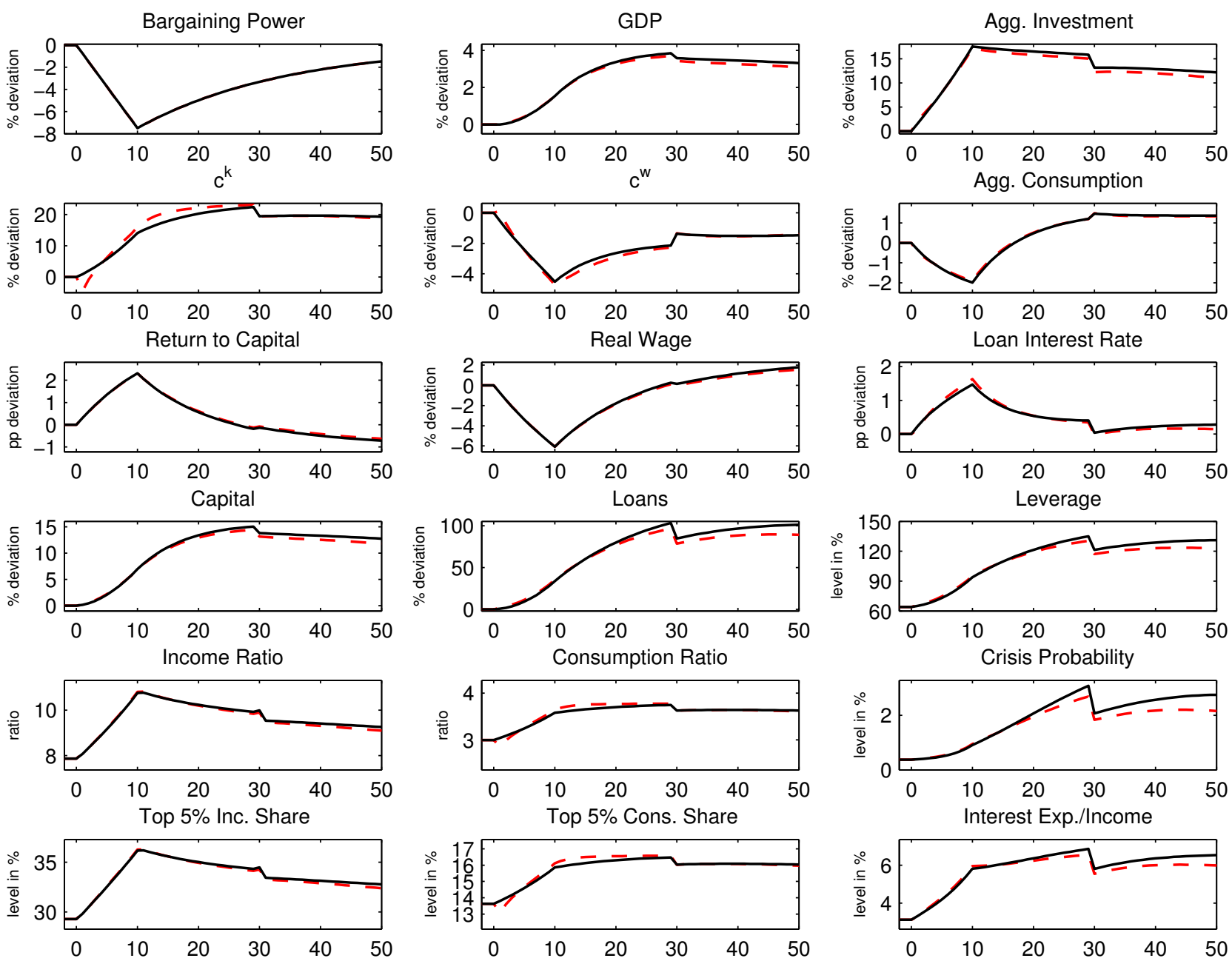
Figure 15. Restoration of Workers' Bargaining Power
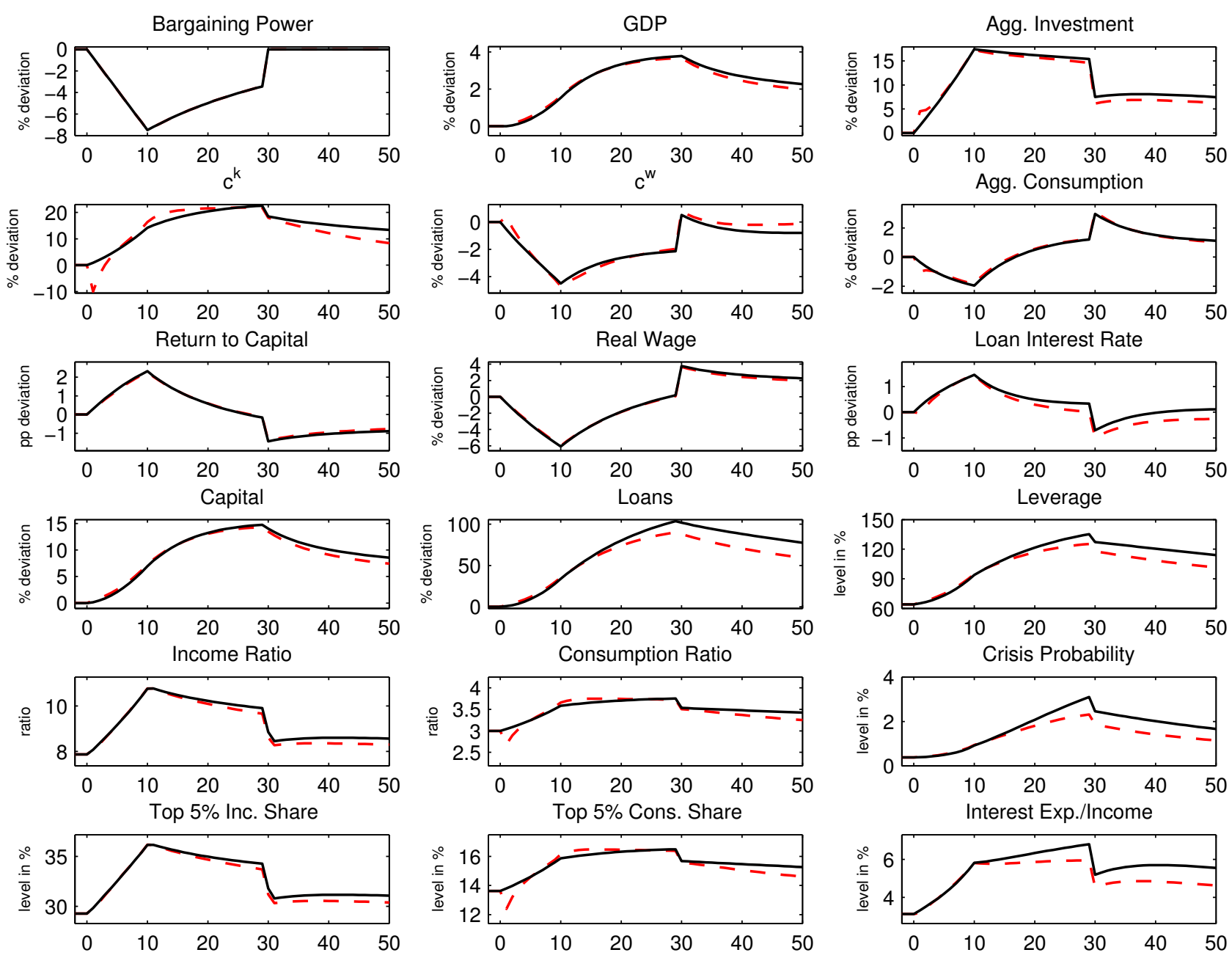